\title{
Swine Housing Facilities
}
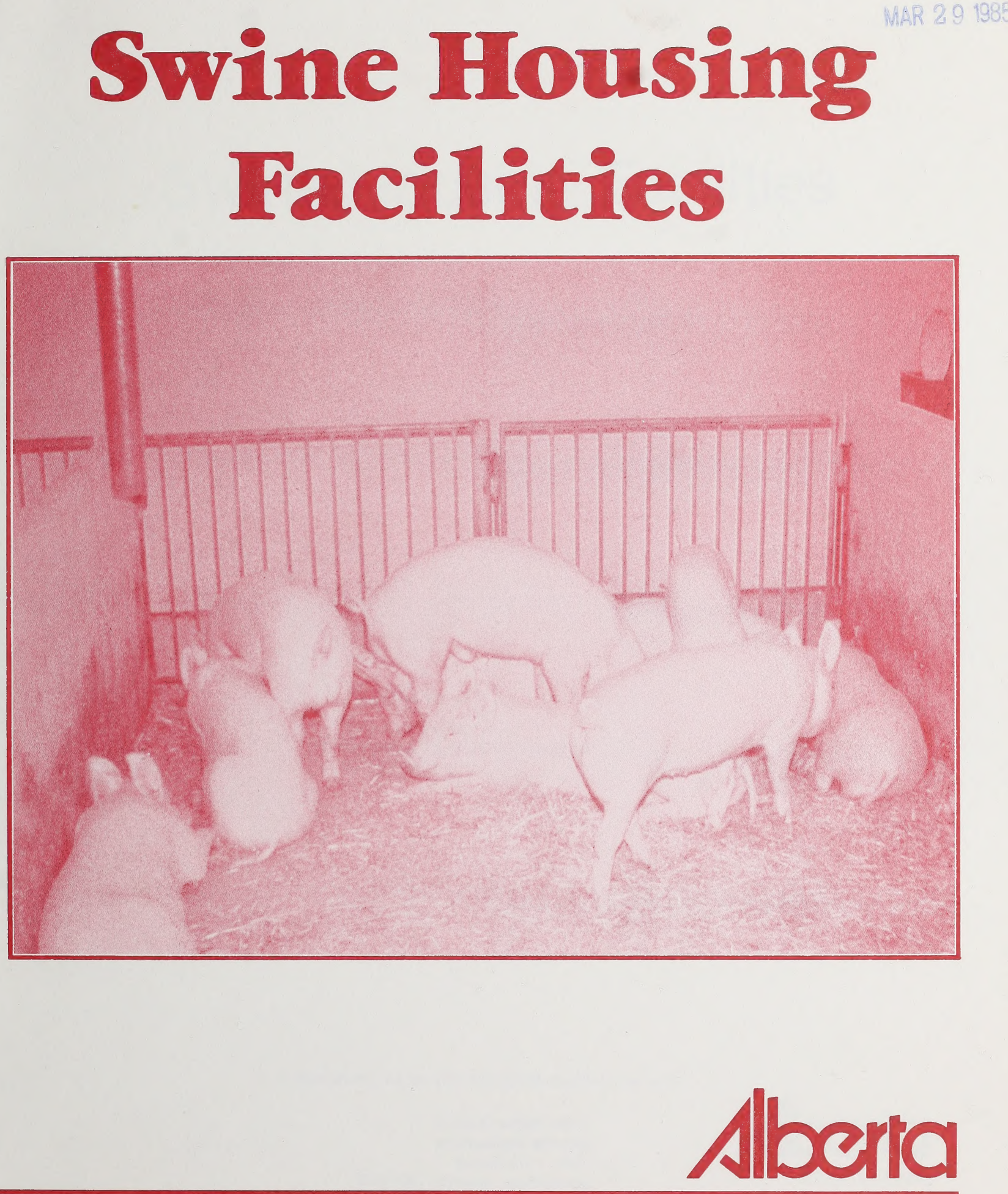

AGRICULTURE

Agdex $440 / 721-I$

$D M N 5329182$ 
Copies of this publication may be obtained from:

Print Media Branch

Alberta Agriculture

7000 - 113 Street

Edmonton, Alberta T6H 5T6

OR

Alberta Agriculture's district offices

Reprinted 198501 3M 


\section{Swine Housing Facilities}

Prepared by:

Brian Kennedy

Regional Agricultural Engineer

Vermilion

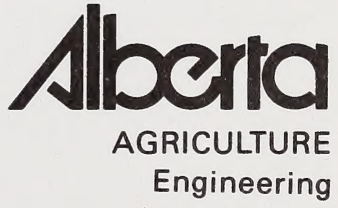




\section{CONTENTS}

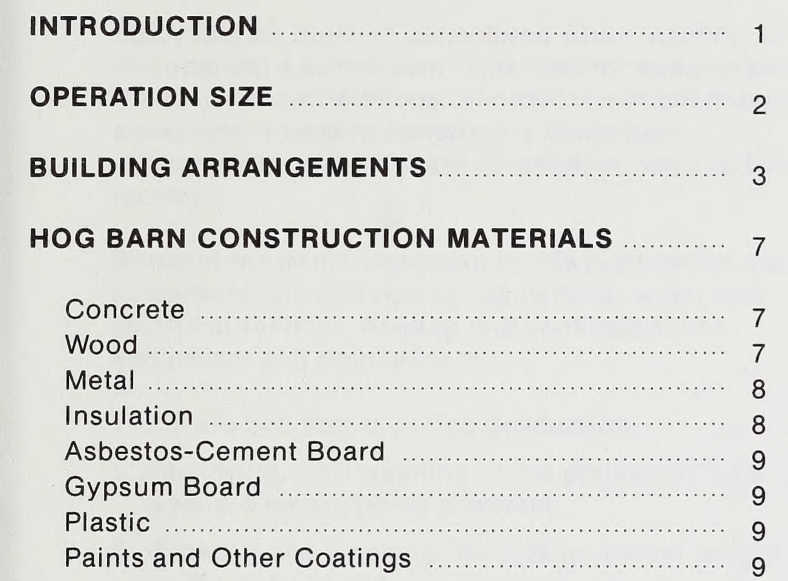

\section{FLOORING MATERIALS}

ELECTRICAL SYSTEM

LIGHTING SYSTEMS

VENTILATION SYSTEMS

Exhaust Ventilation System

Pressurized Ventilation System

Natural Ventilation

21

HEATING SYSTEMS FOR HOG BARNS

WATER SUPPLY

Water Quality

Water Equipment

\section{SIZING THE HOG BARN}

FARROWING HOUSING AND EQUIPMENT 30

Sow Wash

Farrowing Crates 30
HOUSING THE BREEDING HERD

Outdoor Sow Housing .................................... 35

Confined Sow Housing .................................. 35

Environment ........................................ 36

Space Requirements ............................... 36

Water and Feed ......................................... 37

Facilities for New Breeding Stock .................. 37

FEEDER HOUSING AND EQUIPMENT .............. 38

SWINE FEED PROCESSING AND HANDLING ...... 40

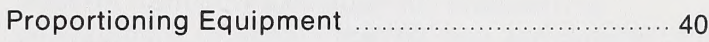

Burr Mills ............................................. 40

Hammer Mills ........................................ 41

Mixers ........................................... 41

FURTHER INFORMATION AVAILABLE FROM ....... 42

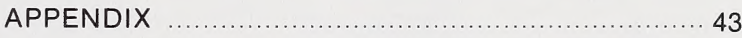


Digitized by the Internet Archive in 2015 


\section{INTRODUCTION}

Many factors must be considered when building or remodelling a swine barn. This chapter looks at some of the major considerations. In order to survive financially, a producer needs to construct a swine barn economically and still have an efficient hog production factory.

Some of the items discussed in this publication are: site considerations and zoning regulations; water and electrical services; heating and ventilation; hog equipment and barn layouts.

There are two stages to hog production:

1. Farrowing, with weaning of the piglets at 3 to 8 weeks, 5 weeks being common.

2. Growing and finishing the pigs to market weight at 22 to 28 weeks of age.

Many farms handle both stages of hog production in a farrow-to-finish operation. Others specialize and produce weaners in a farrow-to-wean operation, or finish pigs to market weight in a finisher operation. When choosing a production system; the decision should be based on the capital available to construct the barn, labor available to operate the system, feed availability, management experience, and personal preference.

Temperature-controlled confinement buildings provide the best swine environment for Alberta conditions. The growing pig, 32 to $65 \mathrm{~kg}$ (70 to $145 \mathrm{lb}$ ), has the most efficient feed conversion at $21^{\circ} \mathrm{C}$, while the finishing pig shows the best feed conversion at $15^{\circ} \mathrm{C}$. Temperatures are not as critical to the breeding herd. Confined swine facilities that include a farrowing area, a weaner area, a grower-finisher area, and a gestation area, are typical. These facilities represent an investment ranging from $\$ 2000$ to $\$ 3000$ per sow (1984 prices).

Regulations of many agencies may dictate building location and waste disposal. A building permit is required from your county or municipality for construction of your barn. Permits for electrical wiring, gas or oil burner installation, plumbing and sewage disposal are also required. Board of Health regulations pertaining to hog keeping will also apply. Construction of any hog barn for 500 or more pigs requires Board of Health approval before construction begins.

Obtaining a Certificate of Compliance is intended to give the farmer some degree of protection should there arise a dispute regarding pollution, provided the operation and level of management are similar to those at the time the certificate was granted.

Several agencies are involved in evaluating a Certificate of Compliance application. Any or all of the following may be involved in evaluating a Certificate of
Compliance:

1. Local government

2. Regional Planning Commission

3. Department of Highways

4. Local Board of Health

5. Department of Environment

6. Department of Labour

7. Alberta Agriculture

Contact your local district agriculturalist for information regarding the Certificate of Compliance program.

Utility services, i.e., water and electricity are essential to a swine operation. Ensure that you have an adequate supply of both at your proposed site. Assistance in evaluating and planning a water supply is available from Alberta Agriculture through the engineering technologist located in the regional agricultural offices.

Accessibility is also a consideration. Good roads and driveways are needed to move feed into the barn and pigs and manure away from the barn.

Most successful swine operations increase their size over time. Plan yours for this future expansion. 


\section{OPERATION SIZE}

The size of your swine operation will depend on many factors. One of the factors often not considered fully is the labor requirements of a hog operation.

A good rule to follow is $80-100$ sows farrow-to-finish per experienced full-time operator. An inexperienced fulltime operator can handle 50-60 sows farrow-to-finish. In a finishing operation a full-time operator can handle 1500-4000 pigs per year. Table 1 provides a guide to the labor requirements for hog production.

\section{TABLE 1 - GUIDE TO HOG OPERATION LABOR REQUIREMENTS}

Farrow-to-Wean

Number of Sows

40

60

100

Farrow-to-Finish

Number of Sows

40

60

100

\section{Feeder Operations}

Number of pigs

500

1000 non-automated

37 man-hr/sow

35 man-hr/sow

20 man-hr/sow

non-automated

45 man-hr/sow

40 man-hr/sow

36 man-hr/sow

non-automated

$1.2 \mathrm{man}-\mathrm{hr} / \mathrm{pig}$

$1.0 \mathrm{man}-\mathrm{hr} / \mathrm{pig}$ automated

20 man-hr/sow

$18 \mathrm{man}-\mathrm{hr} / \mathrm{sow}$

$15 \mathrm{man}-\mathrm{hr} / \mathrm{sow}$

\section{automated}

30 man-hr/sow

26 man-hr/sow

$23 \mathrm{man}-\mathrm{hr} / \mathrm{sow}$

\section{automated}

0.7 man-hr/pig

0.5 man-hr/pig 
BUILDING

ARRANGEMENTS

When planning your hog operation, plan it as a system, keeping in mind possible future expansions. Flow patterns for each of the major products - feed, pigs and manure must be considered. Handle each with a minimum of labor and expense. Keep in mind that the building must provide an optimum environment for both swine and operator.

The first consideration when planning the building system is to determine the intended production volume and the type of operation. Building layout and size are dependent upon number and type of swine housed. The size of the sow herd and the interval between farrowing will greatly influence barn size.

When the system is planned, it is intended to be a specific size. A smaller number of animals can be kept until the operator gains the management experience needed to run the barn at its design capacity. An example of this is to initially use an 8 week farrowing cycle and as experience is gained reduce it to a 6 week cycle. This in effect increases the barn's capacity.

Equipment considered should be durable and simple in design. Availability of repairs must also be considered. Many systems will require considerable maintenance and repair in a short time. Use reliable, pig-proof equipment to minimize maintenance requirements. When design is kept simple, fewer operational problems seem to occur. This is especially true for ventilation, heating, and waste handling. Buildings can be oriented in many different fashions. For smaller operations an inline system may be used. See Figure 1.

T-shaped and L-shaped barns lend themselves to convenient traffic patterns. See Figure 2.

Another alternative is the $\mathrm{H}$-shaped barn. See Figure 3 .

A very large swine enterprise may occupy several individual buildings. These buildings are spaced so that adequate operating space is left between them. Disease and fire control are also considered. See Figure 4.

Every swine barn should have an office for record keeping and a workbench area for light repair work and storage of hand tools. Washroom facilities are

commonly provided. If hired labor is employed, a locker room, shower room and coffee room should also be provided. Space should be left outside the building for employee parking, manure removal, feed delivery and pig loading. All doors to the barn should be locked to keep out unwanted guests.

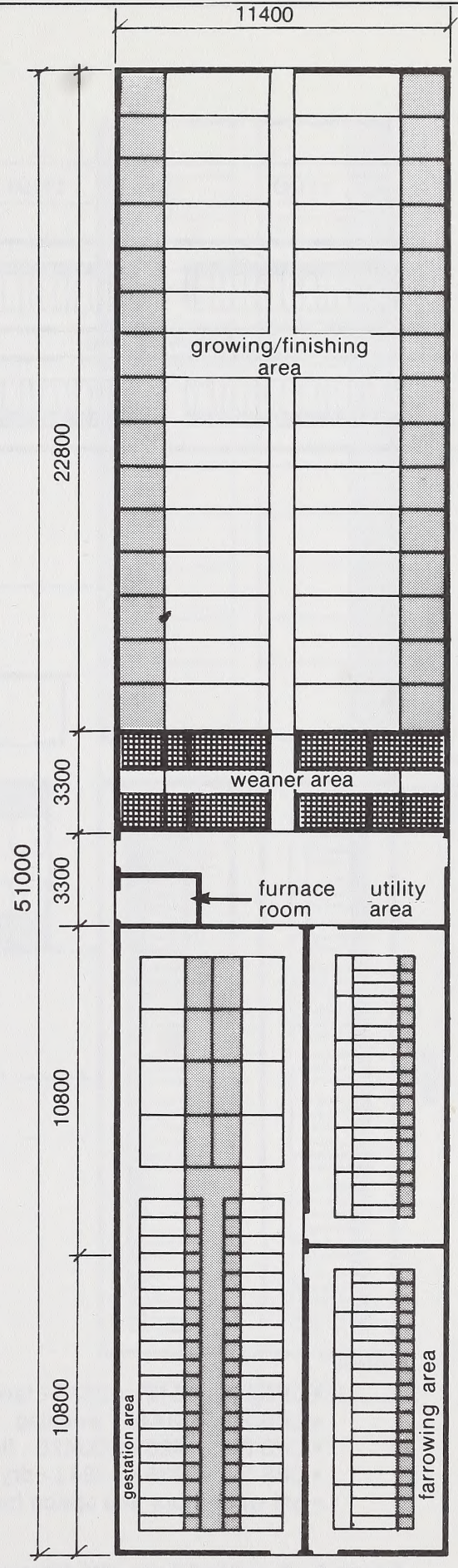

Notes:

- CPS PIan 3428 or Q3429

- hot water floor and space heat

Figure 1 - In line hog barn for 50 sows farrow-to-finish 


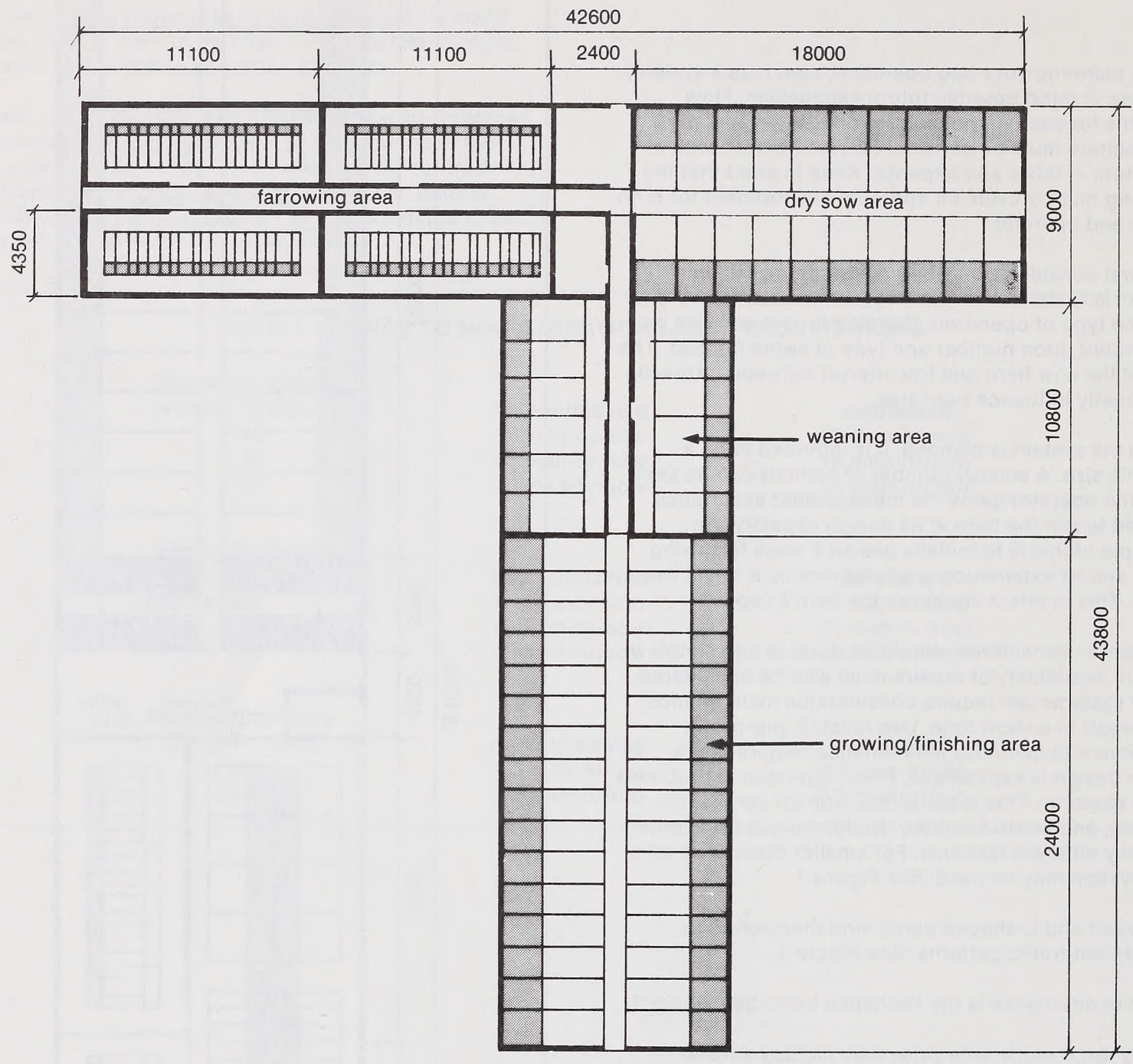

Notes:

- CPS Plan 3312 or 3333 - farrowing

- CPS Plan M3449 - weaning

- CPS Plan 3428 or Q3429 - finishing

- CPS Plan 3236 or 3241 - dry sow

- hot water floor and space heat

Figure 2 - T-shaped barn with farrowing dry sow, weaner and finishing areas for $60-70$ sows 


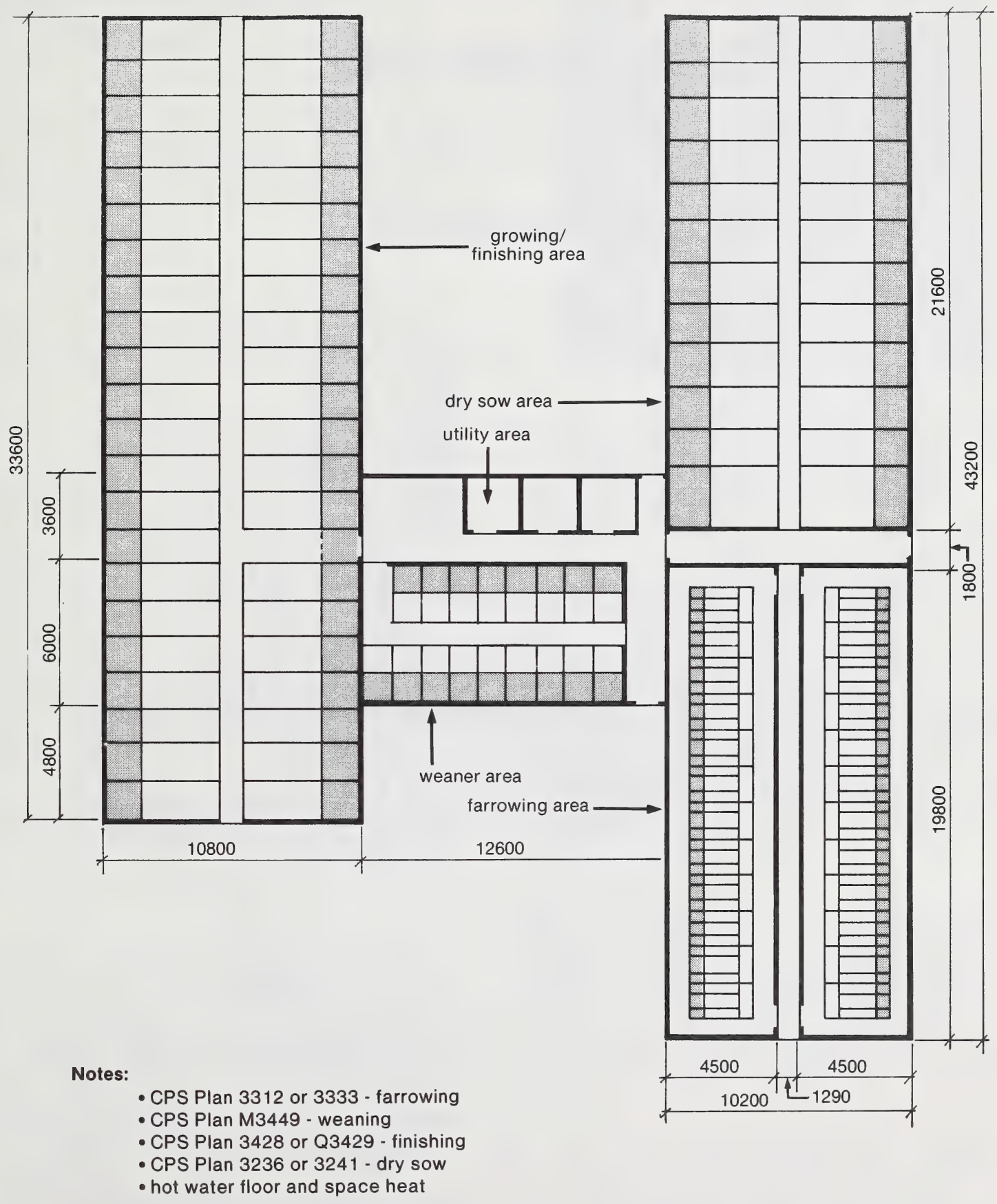

Figure 3 - H-shaped barn for $\mathbf{8 0 - 1 0 0 ~ s o w s ~ i n c l u d e s ~ d r y ~ s o w , ~ f a r r o w i n g , ~ w e a n e r , ~ u t i l i t y ~ a n d ~ f i n i s h i n g ~ a r e a s ~}$ 

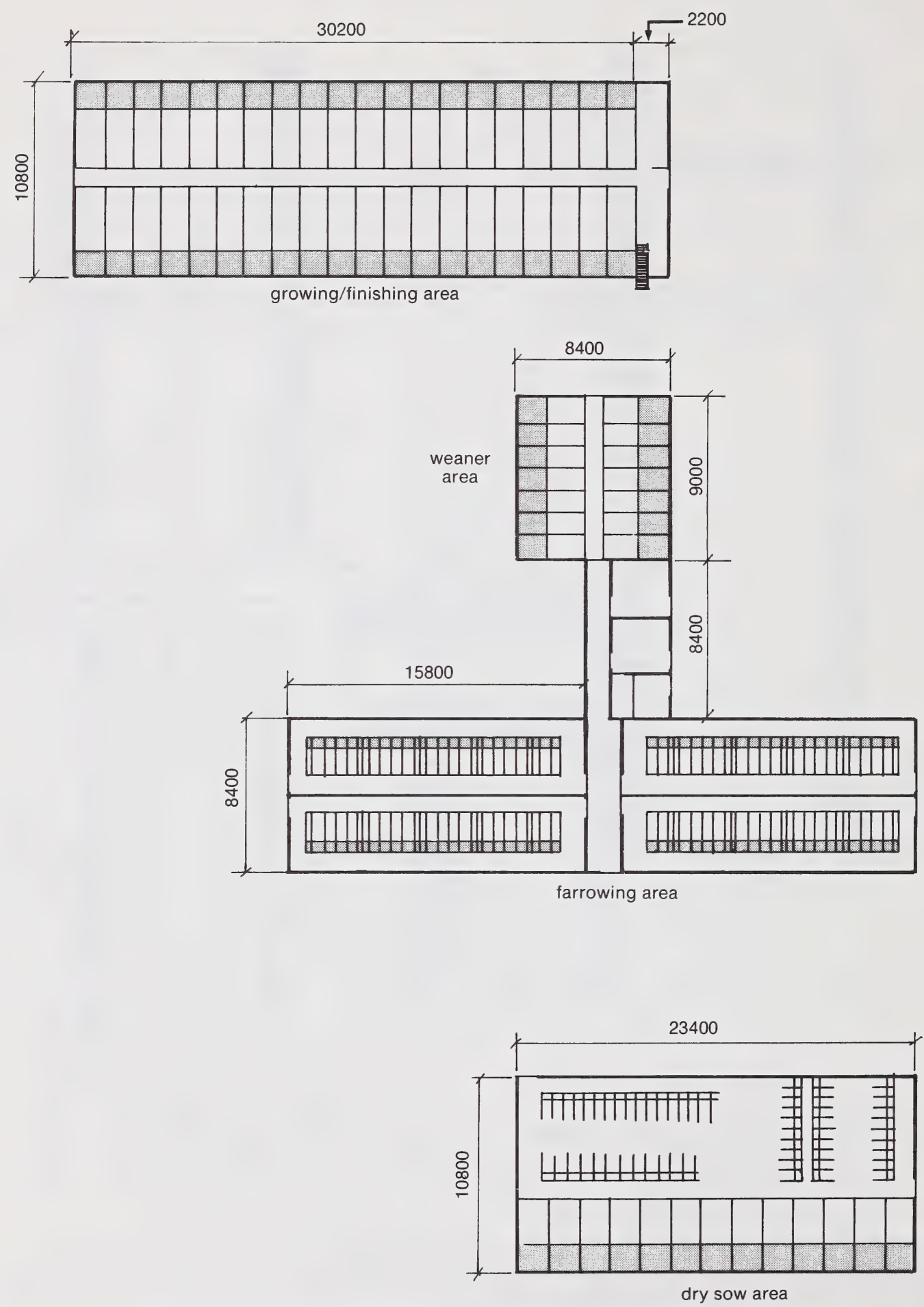

Figure 4 - Farrow-to-finish system, 4 room group farrowing 100 sow herd 
HOG BARN

CONSTRUCTION

MATERIALS

A hog barn is composed of many materials. A list of the major ones might include concrete, wood, metal and insulation. Each of these materials will be discussed in the following sections.

\section{CONCRETE}

Concrete is a mixture of sand and aggregate held together by a hardened paste of cement and water. Concrete is used for footings, foundations, pits, floors and sometimes pen partitions.

Hogs, manure acids, and high pressure cleaning are very hard on concrete. High quality concrete is essential for satisfactory long term performance. A high strength normal concrete is best for most situations. For floors and manure pits, specify $25 \mathrm{MPa}$ strength minimum, 30 $\mathrm{MPa}$ is even better, for high durability. A lower quality $20 \mathrm{MPa}$ concrete is satisfactory for most other areas. All concrete should be air-entrained for maximum durability and freeze-thaw resistance.

Since manure is acid in nature, there is no particular advantage to a sulfate-resistant type of cement, and it is more expensive. Rather, use high quality normal concrete, as noted previously. Do use sulphate resistant concrete, however, for situations where concrete is in contact with alkali soil, such as for pits and tanks.

Floors are normally $100 \mathrm{~mm}$ (4 in.) thick, placed as a slab over a well-compacted base. Slope the floor for proper drainage, usually at a slope of 1:25 (4\%) unless otherwise specified on the plans. The floor is finished to provide a smooth, non-slip surface.

High quality reinforced concrete is required for pits and manure tanks. The size and placement of reinforcing rods provides most of the structural strength, so careful attention to these details is important. Exact design requirements depend on soil conditions, wall thickness, length and height of the concrete wall in question.

Concrete divider walls can also be installed in long manure pits to provide added support against collapse (Figure 5). Dividers can also assist in pit cleaning or manure handling depending on the details of the waste system and barn design.

Quality concrete requires proper placement, finishing and curing. It is desirable to use a concrete vibrator to consolidate concrete in walls and around reinforcing

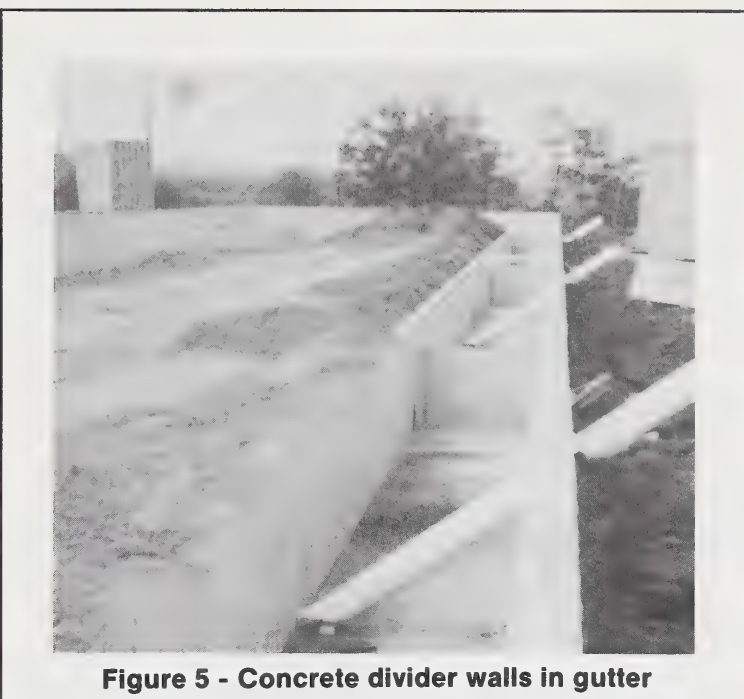

steel. Maximum strength, water tightness and quality are produced when concrete is vibrated into place. After the concrete has been placed and finished, it should be moist-cured for at least three days and preferably longer.

Refer to the bulletin "Concrete on the Farm" (Agdex 715-2) for more detailed information on concrete design, placement, finishing and curing.

Another form of concrete is concrete blocks. Concrete blocks can be used for pen dividers or fire walls.

Concrete blocks should not be used for pits or manure storage structures because of difficulties in keeping the structures water tight. Concrete blocks should not normally be used for the building since they have poor insulating value, however, new masonry systems which have a layer of foam insulation at the core are available.

\section{WOOD}

Wood is a common building material and is typically seen in two forms in hog barns; dimension lumber and plywood. Dimension lumber is used for framing the building. Typically $38 \times 140 \mathrm{~mm}(2 \times 6)$ members are placed $600 \mathrm{~mm}$ (24 in.) on centre for wall framing. Pressure treated wood should be specified where decay is more likely to occur, such as the bottom sill on stud walls. Wooden trusses are usually used for the roof system.

Plywood can be used for both interior and exterior sheathing. Use only exterior grade plywood for hog barn construction. Exterior grade plywood is made with a water-proof glue which can stand up to barn conditions. Typical panel thicknesses are $9.5 \mathrm{~mm}$ ( $3 / 8 \mathrm{in}$.) for interior and exterior wall sheathing and $12.5 \mathrm{~mm}(1 / 2 \mathrm{in}$.) for roof decks. 


\section{METAL}

Various metals are used in hog barns. Sheet metal, either galvanized or enamelled, can be used for roofing and sheathing. It should be fastened to the framing material by metal screws. Aluminum sheet can also be used for sheathing, though special fasteners are needed to prevent galvanic corrosion.

Penning materials are usually mild steel which is painted or galvanized to prevent corrosion.

Several types of metal flooring material are also available.

Sheet metal (galvanized) is also used to protect wood sheathing from the destructive activities of the pigs.

\section{INSULATION}

Swine barns are insulated to limit summer heat gain and to prevent condensation on interior surfaces during winter months. Major insulation types used include glass fibre batts, loose fill and rigid materials.

Insulation efficiency is measured by the RSI factor, which is a measure of the material's resistance to heat flow. The RSI factor has the units of $m^{2} \mathrm{C}^{\circ} / \mathrm{W}$.

Flexible materials (mineral wool, glass fibre or rock wool) are available as batts or blankets in standard widths and lengths. Batt-type or blanket insulation is only used where at least one face is in full, continuous contact with cladding. Insulation must fit snugly along the full width and length of the framing so that a reasonably uniform insulating value results. Flexible insulation is not suitable for use where it would be exposed to the weather or come in contact with water.

Loose fill insulation (blown cellulose, blown glass fibre, vermiculite) is used only on horizontal surfaces. Ceiling and roof construction should be designed to prevent loose fill insulation from spilling into the soffits, blocking ventilation. Cardboard insulation stops are available to prevent this from occurring. Figure 6 shows the installation of an insulation stop.

Rigid insulation materials (extruded polystyrene) are used to insulate foundations and to form air inlet baffles. All rigid insulation materials used in a hog barn must be water resistant. Rigid insulation can be attached to concrete with ramset fasteners, or it can be bonded with concrete grout or with adhesives. An adhesive that does not deteriorate or attack the insulation must be used. Exposed portions of the foundation insulation should be protected with asbestos-cement board, or stucco on wire lath. This protects against mechanical damage to the insulation material. Figure 7 shows rigid foundation insulation covered with stucco wire to hold a concrete parging.

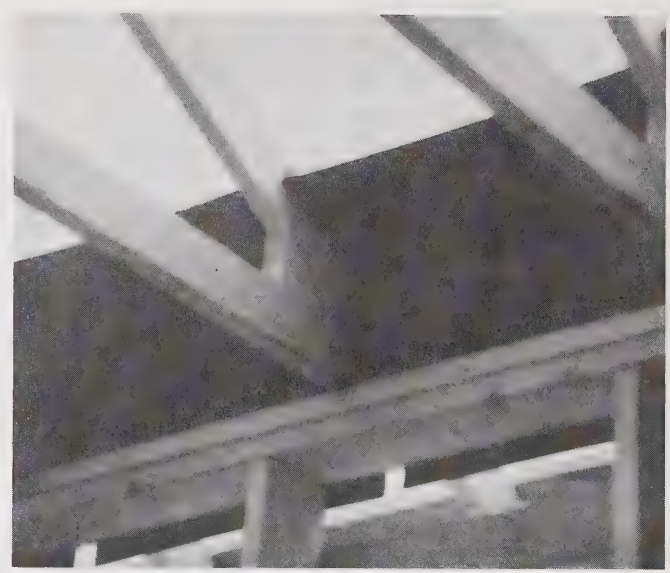

Figure 6 - Cardboard insulation stop
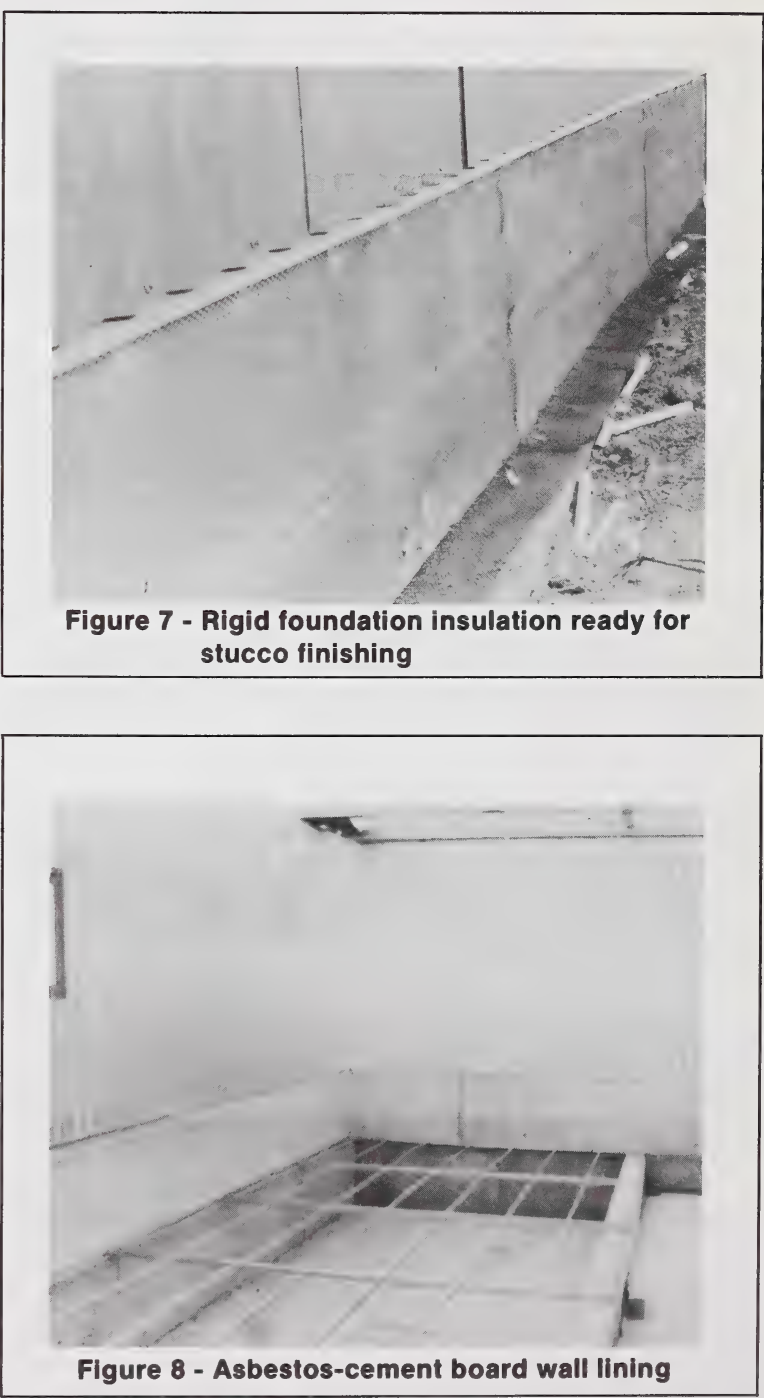
1.4 (R8). Foundation insulation inhibits frost

penetration, preventing either thermal stress of the

structure or frost heave of the floor and foundations.

\section{ASBESTOS-CEMENT BOARD}

Asbestos-cement board is a product made of Portland cement and asbestos fibres. It is fire resistant, strong. water resistant, permanent and impervious to rot, mold, fungi, insects and swine. It is used to protect interior sheathing any place that the hogs may contact it. It is also used as a fire resistant lining for the furnace room. Figure 8 shows asbestos-cement board used as a wall panelling on the lower portion of the wall.

\section{GYPSUM BOARD}

Gypsum board may be used as a fire resistant material to line the furnace room. It should never be used where it will be exposed to damp conditions. It is not durable enough for most other applications in barn construction.

\section{PLASTIC}

Plastics are used for a variety of purposes in the hog barn. One very important use is the vapor barrier. It should be a $0.15 \mathrm{~mm}$ ( $6 \mathrm{mil}$ ) continuous plastic sheet placed on the warm side of the wall and ceiling.

Other uses for plastic materials include water lines and flooring systems in weaner decks, farrowing crates or floor slats.

\section{PAINTS AND OTHER COATINGS}

Paints are made of two constituents; a finely ground solid known as the pigment, and the liquid portion called the vehicle or medium. Use barn paint or a good quality, high gloss, exterior paint. Do not use a lead base paint. Gases present in a hog barn will react with it to produce a very dark surface. The pigs will also eat the paint which will give them lead poisoning.

Fibreglass resin has been successfully used to coat wooden creep panels. It provides a smooth, durable, easy to clean surface.

\section{ARENA BOARD}

$3 \mathrm{~mm}\left(1 / 8^{\prime \prime}\right)$ or $6 \mathrm{~mm}\left(1 / 4^{\prime \prime}\right)$ plastic panels used as a protective covering for barn walls in contact with pigs. It has the disadvantage of a high coefficient of expansion and therefore should be applied to the building at near room temperature. 


\section{FLOORING MATERIALS}

Many types of flooring materials are available to the hog producer. Using perforated floors in swine housing is standard practice. Some materials have been developed for this purpose; some have been developed for other purposes, but are suitable for flooring material for swine.

Before looking at specific materials it may be of value to state the performance specifications of floors for pigs. They are:

1. Floors should not cause injury to livestock. They should provide a nonslip, nonabrasive surface with no sharp or protruding edges.

2. Floors should not harbor disease-causing parasites or bacteria. Surface should be impervious and readily cleanable.
3. Floors should not cause stress or discomfort which might manifest itself in depressed growth, poor feed conversion or abnormal behavior.

4. Floor materials should not deteriorate or become deformed during their planned life, nor should they require maintenance during this time.

5. Perforated floors should not retain manure or urine, which would require scraping.

6. Floors should meet the above requirements at a reasonably low cost.

For purposes of this discussion, flooring materials will be classified as follows:

1. Reinforced concrete slats.

2. Steel meshes.

3. Plastic products, including plastic coated metals, and

4. Other slats, such as fibreglass, stainless steel, and cast iron products.

\section{SLAT SPAN}

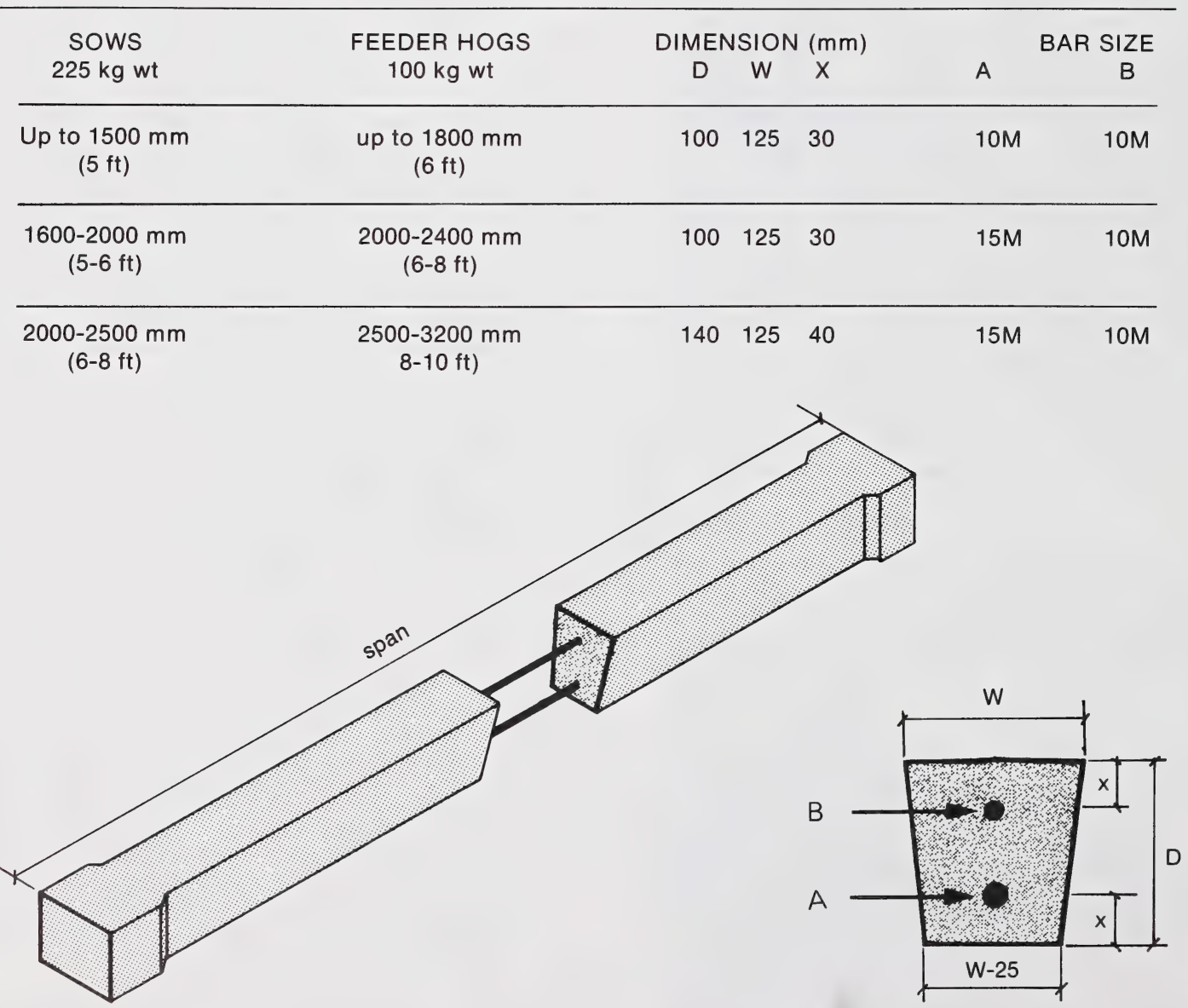

Figure 9 - Reinforced concrete slats 


\section{REINFORCED CONCRETE}

Reinforced concrete slats are available as precast individual slats, (various lengths), precast floor panels, or they may be cast in place.

Cast in place reinforced concrete slats should be made of $30 \mathrm{MPa}$ ( $4500 \mathrm{psi}$ ) concrete with an $18 \mathrm{~mm}$ ( $0.75 \mathrm{in}$.) maximum aggregate size. Reinforcing steel is needed to provide adequate structural strength. If the slats are to be moved after casting two rebars are needed. See

Figure 9.

The upper bar is to prevent breakage when the slat is moved. The lower bar is to provide sufficient strength to hold the animal's weight. A slight crown, and pencil rounded edges should be formed on the slat when it is cast.

\section{STEEL MESHES}

Details of common steel meshes used in pig housing are given in Table 2. Steel mesh products may require the addition of supports, as recommended by the manufacturer.

Steel meshes have good self-cleaning properties because of the high void-to-solid ratio. Some of the meshes are available in galvanized form. This may give some initial protection against corrosion. Some galvanizing processes leave drips on the surface of the material; these projections are sharp and may cause injury.

\section{PLASTIC PRODUCTS}

Plastic materials are generally durable and not affected by urine or feces. Animals may find difficulty in finding footing when the material becomes wet. Table 3 lists some of the common plastic products.

TABLE 2 - STEEL MESH HOG FLOORING PRODUCTS

Material Type

Flattened expanded metal

Welded wire

$5.3 \mathrm{~mm}$ wire@12.5 mm OC

$5.3 \mathrm{~mm}$ wire@15 mm OC

$5.3 \mathrm{~mm}$ wire@18 mm OC

Woven wire

Steel rods

$10 \mathrm{~mm}$ diameter (with

$10 \mathrm{~mm}$ gap)

Prepunched metal planks
60

Void (\%)

60

$60-68$

47

26

\section{Application \& Comments}

- support @ 300 mm OC; not suitable for farrowing pens with piglets less than 14 days old; limited life span unless well supported; keeps clean; suitable for flat decks.

- support @ 300 mm OC; suitable for farrowing pens; some sows have difficulty in gaining a foothold; can be used for weaner decks.

_ support @ 300 mm OC; suitable for farrowing pens: low incidence of piglet foot and leg injury at birth.

- self supporting to $1200 \mathrm{~mm}$; suitable for farrowing crates; low incidence of piglet foot and leg injury.

- self supporting to $1200 \mathrm{~mm}$; indented holes may reduce piglet foot and leg injury; sows tend to have difficulty in gaining secure foothold; suitable for flat decks. 


\section{TABLE 3 - PLASTIC HOG FLOORING PRODUCTS}

\section{Flooring Material \\ Plastic coated unflattened expanded metal}

Pre-punched extruded plastic

Plastic coated metal planks

\section{Voids (\%) Comments \& Application}

26

- support at $300 \mathrm{~mm}$ centres; is available in two sizes, one for farrowing crates and a smaller size for weaner decks.

17

- support at $600 \mathrm{~mm}$ centres, sows may have difficulty in gaining footholds; low incidence of piglet injury; suitable for weaner decks.

- self supporting to $1200 \mathrm{~mm}$; suitable for flat decks.

\section{OTHER MATERIALS}

Included in this classification are homemade metal slats, fibreglass slats, stainless steel slats, and cast iron slats. Table 4 lists some other materials.

The sample of floor types listed is not exhaustive, but it does represent most of the types presently in use. Examples of different floor types are shown in Figures 10 to 15 . Because the requirements of pigs vary with growth, no one floor is likely to be suitable for all classes of stock. In general, concrete slats are the most suitable for dry sow housing and in growing finishing accommodation for pigs larger than $20-25 \mathrm{~kg}(45-55 \mathrm{lb})$ live weight.

Provided meshes are properly supported using them in farrowing crates and weaner decks is satisfactory. Using expanded metal causes foot and leg problems in piglets from birth to 14 days of age.

It is difficult to account for all of the pigs' requirements when comparing floors. The incidence of injury and disease may be as much due to stocking density and biological factors as to the structural properties of the floor.

TABLE 4 - OTHER HOG FLOORING MATERIALS

\section{Flooring Material}

Homemade Metal Slats

Stainless Steel

Fibreglass T Slats

\section{Comments and Applications}

$-6 \mathrm{~mm}$ steel straps placed $9 \mathrm{~mm}$ apart have worked well in farrowing crates and dry sow barns.

- slotted flooring, $300 \mathrm{~mm}$ wide, self supporting to $300 \mathrm{~mm}$, used in farrowing crates and weaner decks.

- $38 \mathrm{~mm}$ slats spaced $9 \mathrm{~mm}$ apart are used for weaner areas; can also be used in farrowing crates and finishing barns.

- self supporting to $1200 \mathrm{~mm}$, suitable for all classes of swine. 


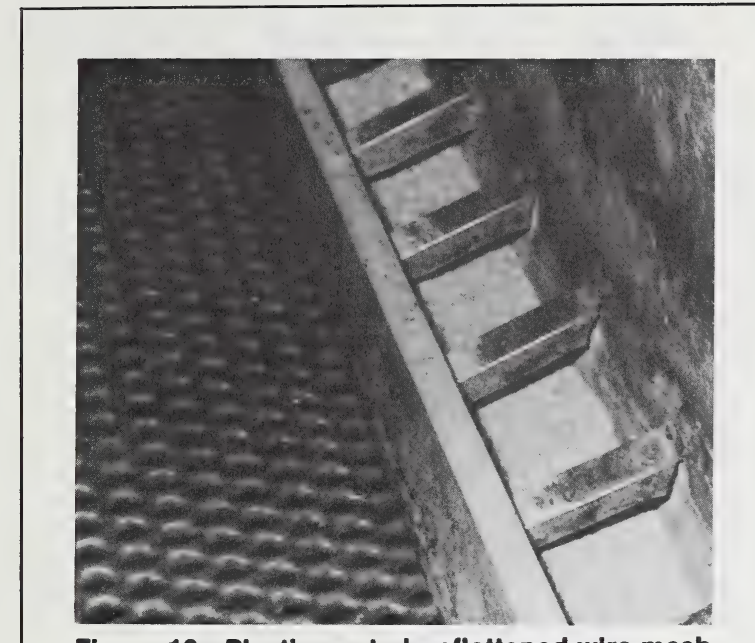

Figure 10 - Plastic coated unflattened wire mesh

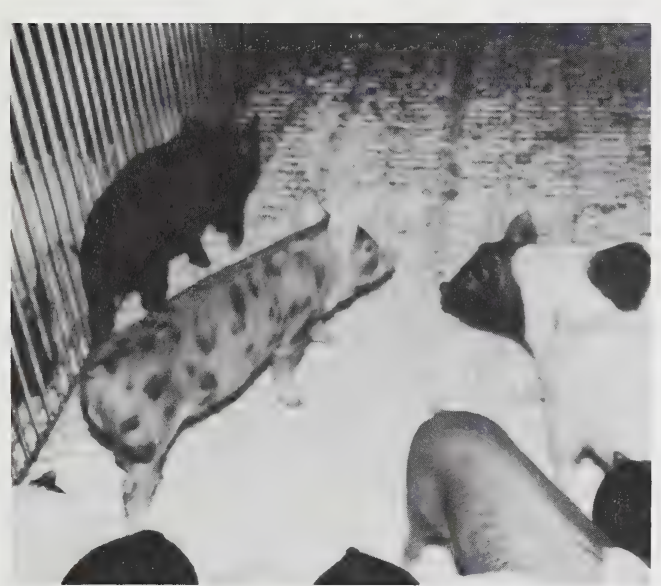

Figure 12 - Plastlc floor panels under a weaner pen

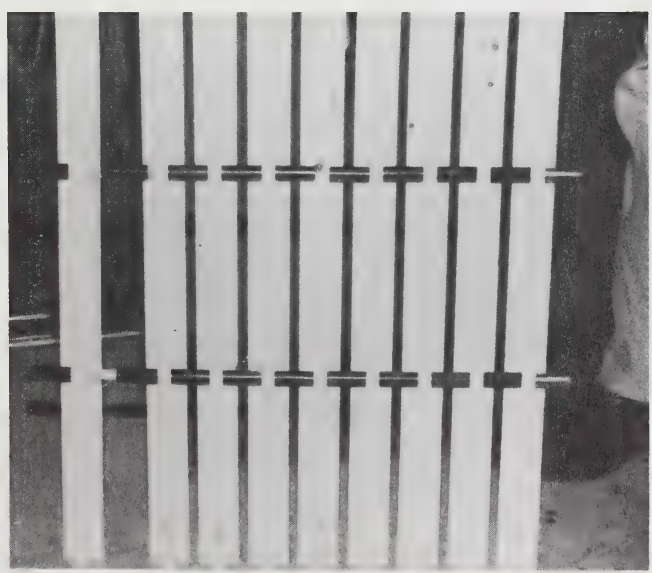

Figure 13(b) - Fibreglass T slats (bottom view)

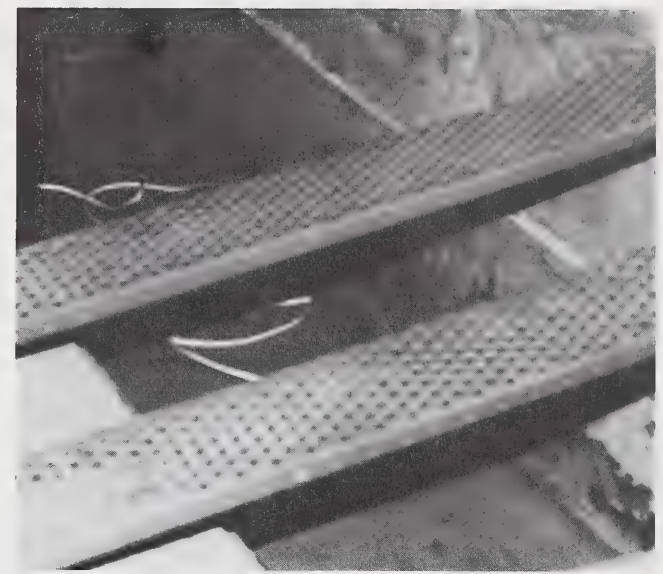

Figure 11 - Plastic coated perforated metal planks

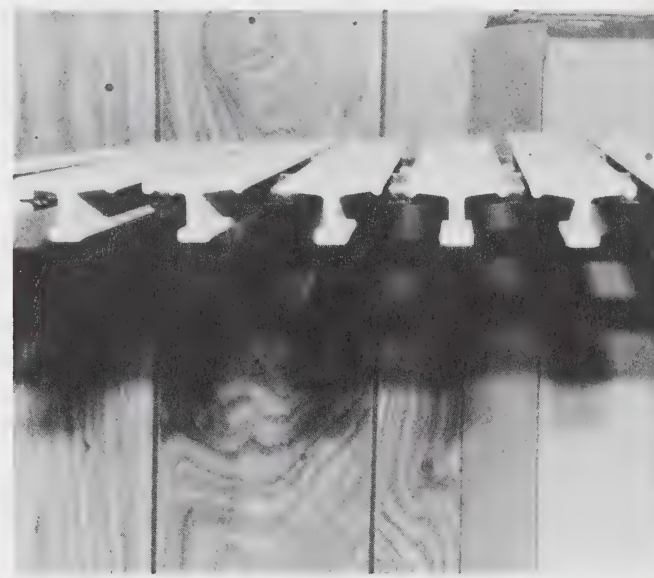

Figure 13(a) - Fibreglass T slats (end view)

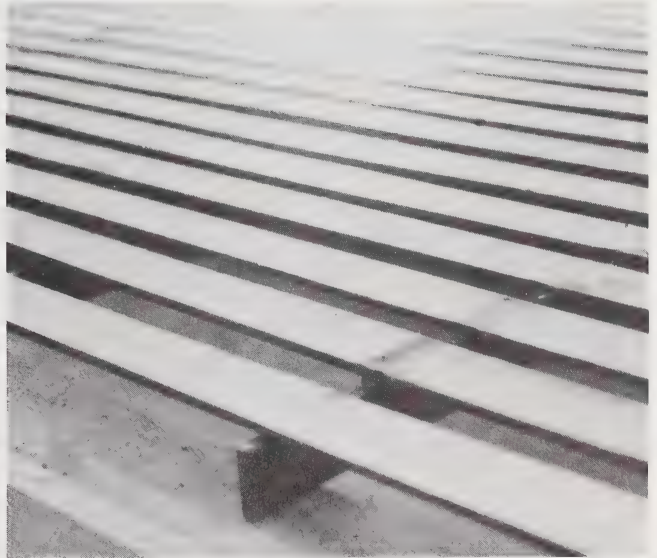

Figure 14 - Homemade slats made of flat iron 


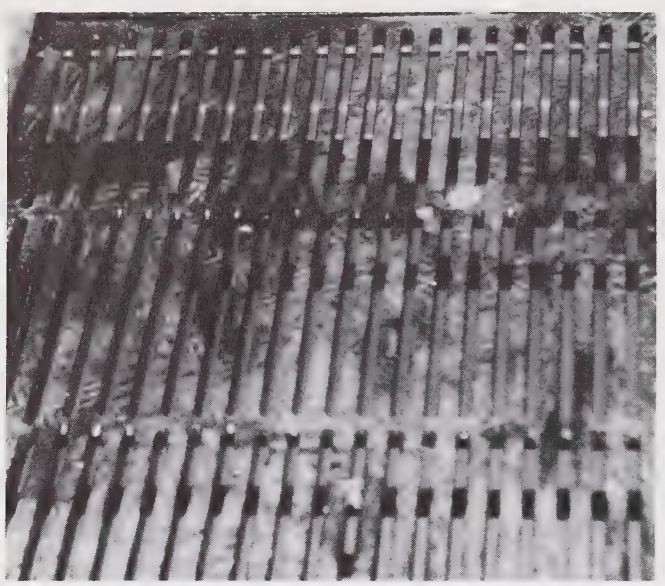

Figure 15(a) - Cast iron slats

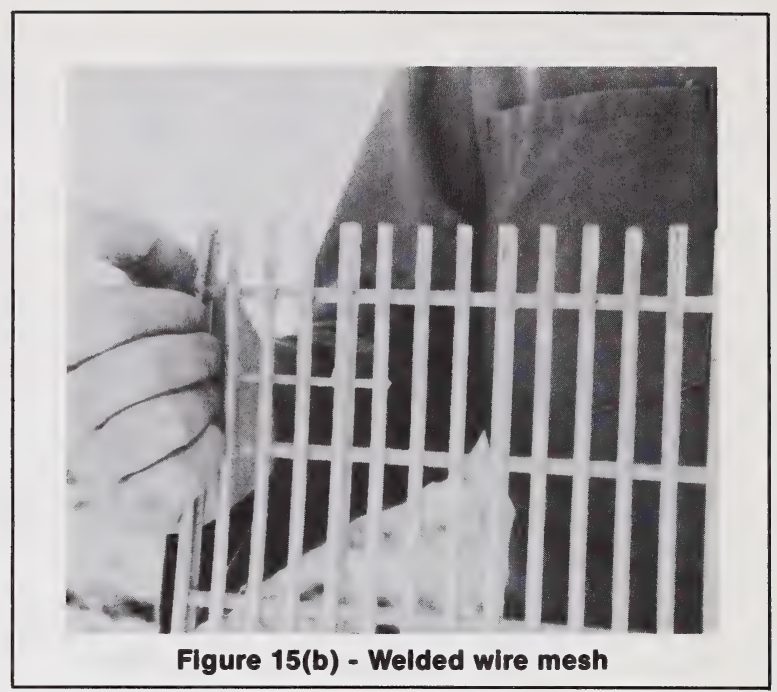




\section{ELECTRICAL SYSTEM}

The electrical system is the energy source for operating the barn. It provides the energy to provide light, operate ventilating systems, heating systems, feed conveyors and do other tasks.

Electrical energy is delivered to the barn as 240 volt -60 cycle energy. A service entrance brings the electricity into the barn. Place the service entrance in a dry location, such as the furnace room. Figure 16 shows a service entrance in a large modern hog barn. Branch circuits then distribute electrical energy within the barn. Provide a separate circuit for each ventilation fan (in event of a short in the circuit then only one fan is affected).

Swine barns should be wired for damp conditions using NMW wire and bakelite or plastic boxes, all surface mounted and preferably in plastic conduit.

Auxiliary or standby power is a wise investment. It may be an automatic unit sized to power the whole barn in case of a power outage, or a manually operated unit that powers only essential ventilation, lighting and heating equipment. A double-pole double-throw switch is used to connect the auxiliary plant to the barn's electrical system. Figure 17 shows an automatically controlled, engine-driven standby system.

All electrically operated equipment must be CSA approved. When purchasing electrically operated equipment for your barn, check the label to be sure it is CSA approved.

All wiring in the barn must meet the requirements of CSA C22.1 - 1982 - Canadian Electrical Code Part 1, as well as provincial supplements. A wiring permit, available from your local electrical inspector, is required for the installation of the electrical system. The owner may obtain a permit to do his own wiring of systems up to $100 \mathrm{~A}$ service; larger sizes require the permit be taken out by an electrical inspector.

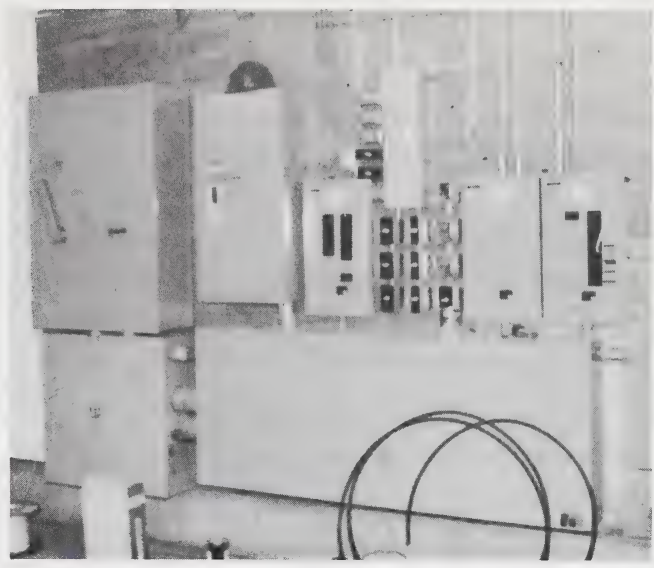

Figure 16 - Main electrical service entrance

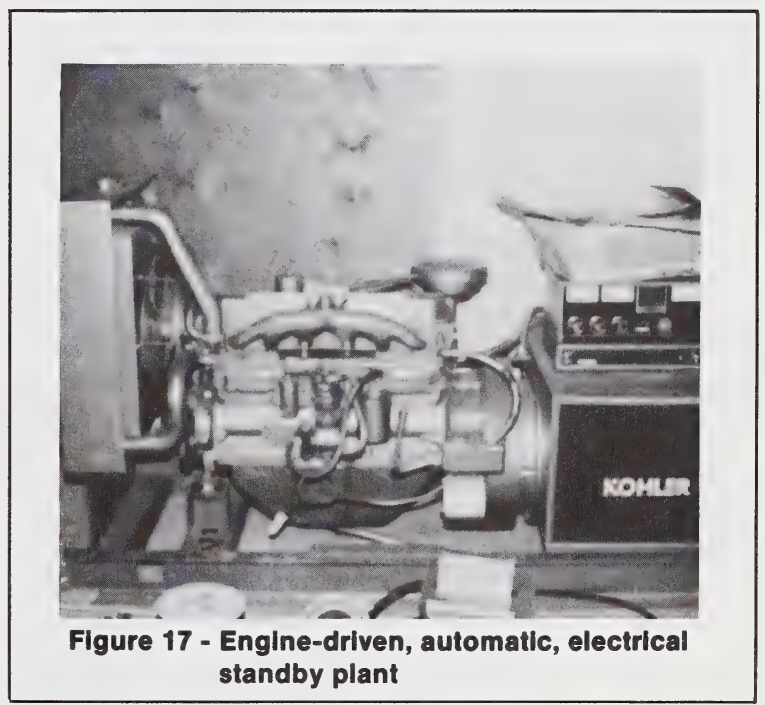




\section{LIGHTING SYSTEMS}

Provided glare is controlled, the better the light level, the better we see. The problem is to select light levels adequate to perform particular tasks with ease and comfort.

General guidelines for the lighting of hog barns are:

1. Paint the walls and ceiling with a light colored reflective coating.

2. Provide illumination levels as shown in Table 5.

3. Provide light where it is needed.

4. Use diffusing sources to reduce glare.

5. Maintain the system, clean fixtures frequently, replace burned out and old lamps.

Luminaires (lighting fixtures which hold one or more lamps) in the hog barn should be resistant to damp, corrosion and mechanical damage. In the barn where surfaces are washed down with a high pressure hose, luminaires should be water proof. Sealed, or totally gasketed, luminaires are available for both fluorescent and incandescent lamps. See Figure 18.

Recent research has shown that adding light to a confinement gestation barn will promote estrus in gilts. A light period of 14-18 hours per day at a level of 100200 lux (10 to 20 foot candles) is needed. This lighting regime can also increase the number of piglets farrowed per litter.

A good general rule of thumb is to provide one

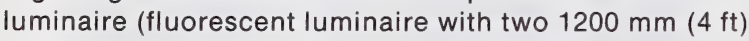
lamps, or equivalent) for every two pens.

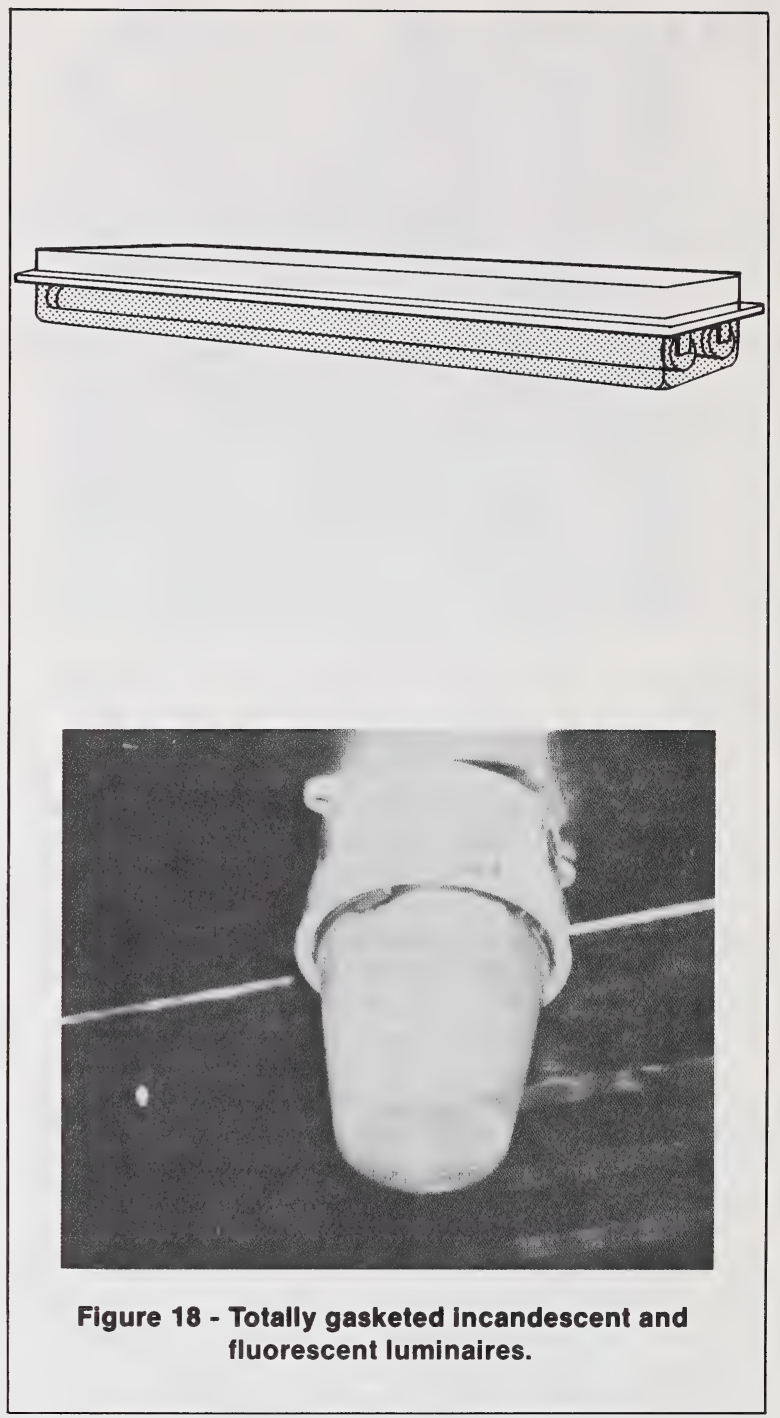

TABLE 5 - MINIMUM LIGHT LEVELS FOR HOG BARNS

\begin{tabular}{lrl}
\hline Area & Minimum Illumination \\
Office & $750 \mathrm{lux}$ & Provide 760 lux for reading tasks at the desk. \\
Furnace Room & $100 \mathrm{lux}$ & Supplementary light needed for equipment repair. \\
Washroom & $325 \mathrm{lux}$ & \\
Farrowing Barn & $220 \mathrm{lux}$ & Localized lighting needed for some tasks. \\
Grower-Finisher Barn & $220 \mathrm{lux}$ & \\
Gestation Barn & $100-200 \mathrm{lux}$ & On time clocks to provide a daily light period of \\
Outdoor Areas & 10 lux & $14-18$ hours.
\end{tabular}




\section{VENTILATION SYSTEMS}

Ventilation and heating systems in a swine barn provide a suitable environment for the pigs. Ventilation removes moisture, heat, and gases and provides fresh air for the pigs. In winter, ventilation removes excess moisture produced by the animals. In the summer, ventilation removes excess body heat. Both the ventilation and heating systems must be designed together for an individual building based on animal numbers and insulation values.

The essentials of a ventilation system are:

1. Insulation RSI 3.5 (R20) minimum in walls and ceiling; RSI $1.4(\mathrm{R} 8)$ foundation

2. Vapor barrier (to protect insulation and structure from moisture vapor)
3. Inlets (to direct and distribute incoming air)

4. Fans and controls (to remove air and control volume removal)

5. Management

Ventilation systems can be divided into three groups:

1. Exhaust systems function because of a negative static pressure owing to the use of exhaust fans. The exhaust fans create a slight vacuum inside the building.

2. Pressure systems, in which fans force air into a building through an inlet to create a positive static pressure. The inlet fans pressurize the inside of the building slightly.

3. Natural ventilation systems function because of the natural buoyancy of warm air and the effect of wind pressure.

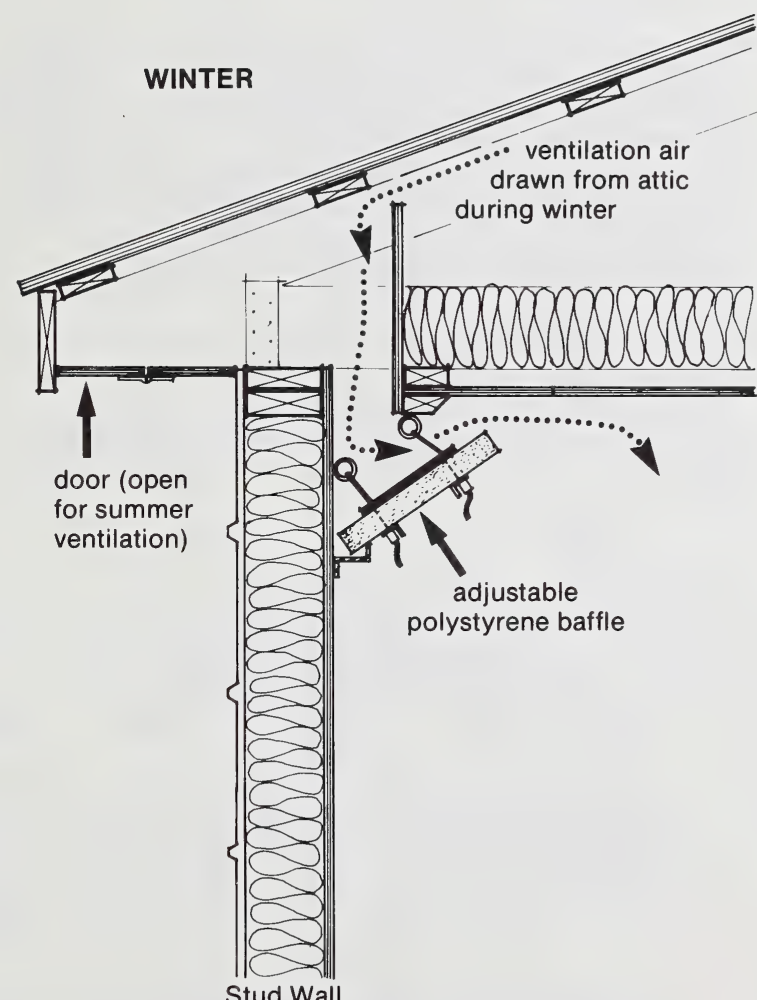

Stud Wall

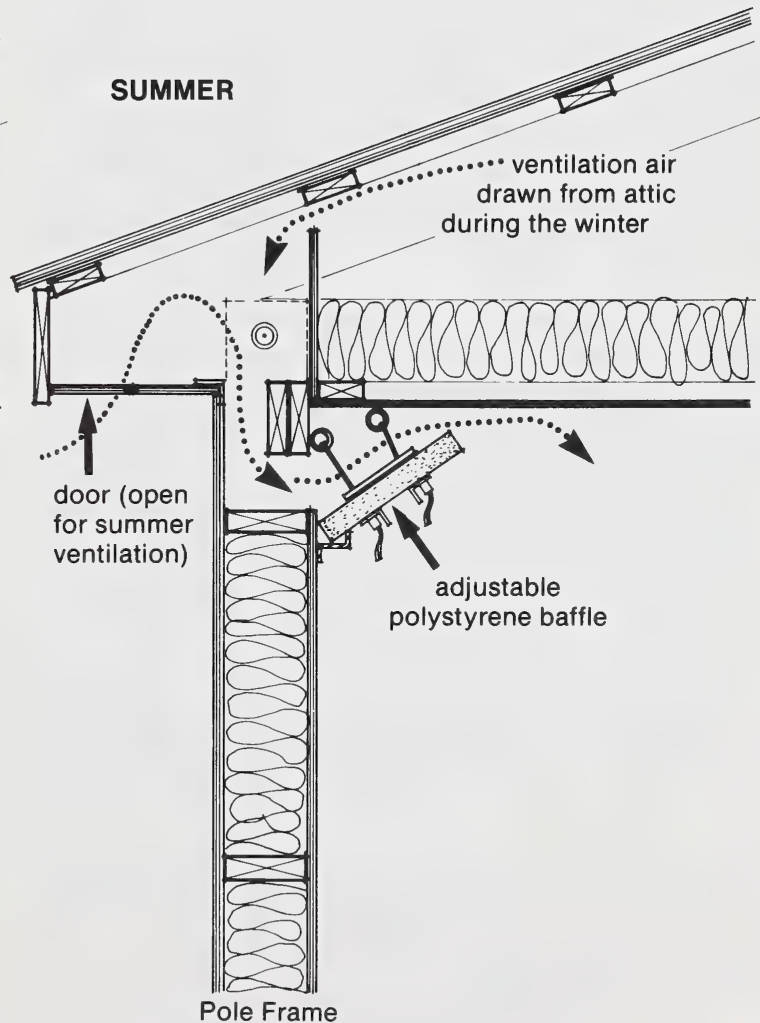

Figure 19 - Side air inlet, CPS Plan 9714 


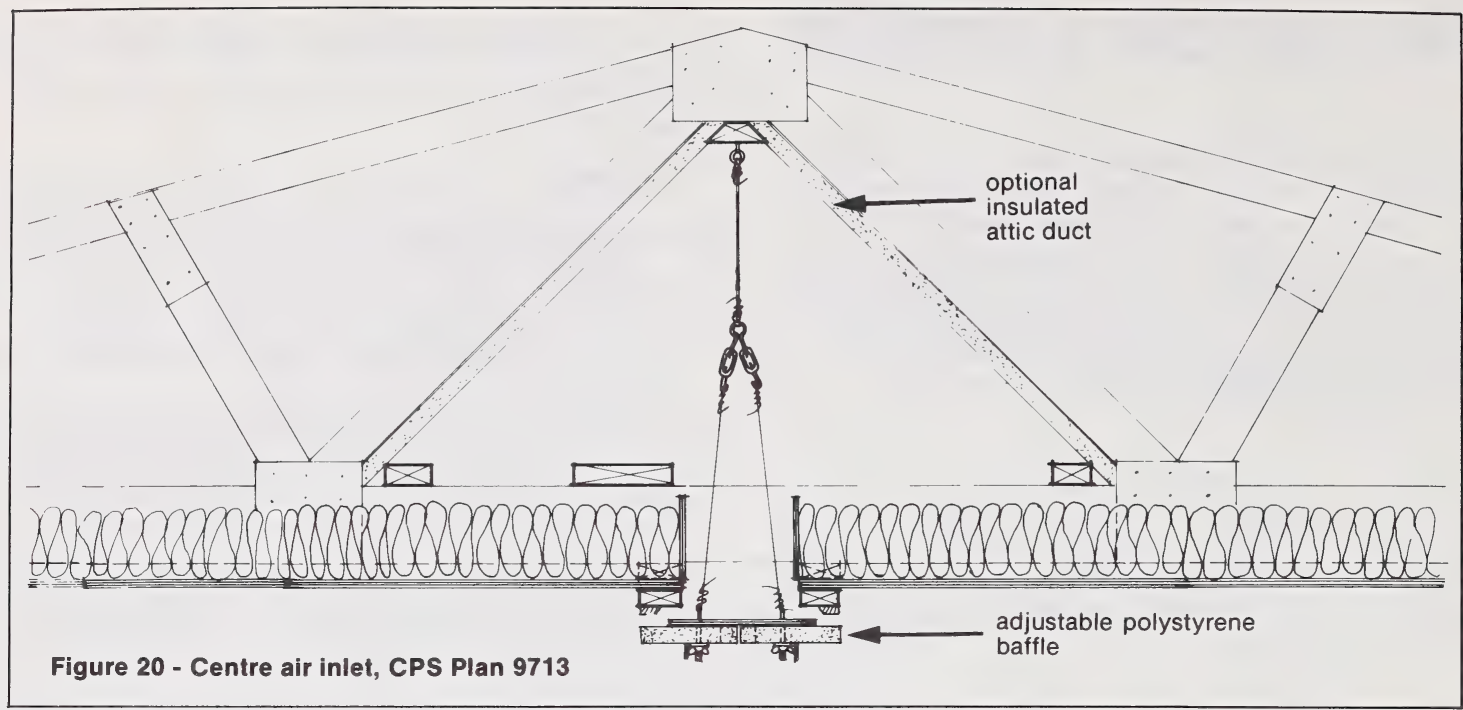

\section{EXHAUST VENTILATION SYSTEM}

Normally, exhaust ventilation systems operate at 1 to 2 $\mathrm{mm}$ (0.04 to $0.10 \mathrm{in}$.) of static pressure across the inlet to produce an inlet velocity of $5 \mathrm{~m} / \mathrm{s}(1000 \mathrm{ft} / \mathrm{min})$. This pressure causes air to rush into the building through the inlets which control incoming air. In most building layouts exhaust systems are most convenient to install and operate. Inlets may be located along the side of the building (side air inlets) or along the centre of the building (centre air inlets). Figure 19 and 20 show these air inlets.

Inlet locations are chosen so that cold incoming air is directed over the manure gutter. This encourages the pigs to manure over the gutter. As the cold incoming air moves into the barn it picks up the heat and loses velocity. This reduces drafts directly on pigs. To achieve correct ventilation patterns, side air inlets are used in narrow buildings of less than $10 \mathrm{~m},(33 \mathrm{ft})$ or in buildings that have a centre manure gutter, and centre air inlets are used in buildings wider than $10 \mathrm{~m}$ ( $33 \mathrm{ft}$ ), or in buildings with manure gutters along the outside walls.

To achieve correct ventilation patterns the ceiling of the barn must be free of obstructions to prevent undesirable currents. If metal sheathing is used, orient the ribs parallel to the airflow.

The inlet should be located at the ceiling, as opposed to in the wall, because the air current will stick to the ceiling for a greater distance and create a more desirable air flow pattern.

Inlets need to be adjusted seasonally and daily. The objective is to maintain a minimum inlet velocity of 4-5 $\mathrm{m} / \mathrm{s}(800-1000 \mathrm{ft} / \mathrm{min})$. Speeds below this do not give the incoming air enough energy to create desirable air flow patterns. Suitable air flow patterns can be achieved by operating the system with 2 to $3 \mathrm{~mm}$ (0.08 to $0.10 \mathrm{in}$.) static pressure. A simple manometer can be constructed to indicate the pressure. Alternatively,

automatic controls can be purchased that sense static pressure and adjust the inlets.

Fans are air pumps that pump air out of the building to create a static pressure. Propeller fans are commonly used in agricultural buildings. Normally fans are chosen for their capacity at $3.2 \mathrm{~mm}(0.125 \mathrm{in}$.) of static pressure. About one-half of this pressure drop is across the inlets, the rest is across the fan, especially if it has automatic louvers. Unmaintained (dirty) fans can have their capacity reduced by at least $30 \%$ by dust build up.

Contrary to popular belief, fans do not create air currents. Rather, it is the air inlet system that determines air flow patterns in a building. Until air coming from the inlet gets close to the fan, there is no noticeable air movement towards the fan. See Figure 22. 22.
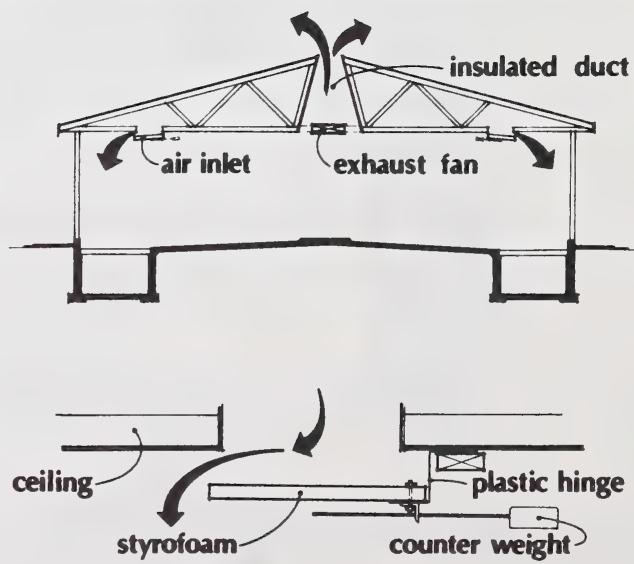

Figure 21 - Automatic Air Inlet Baffle 


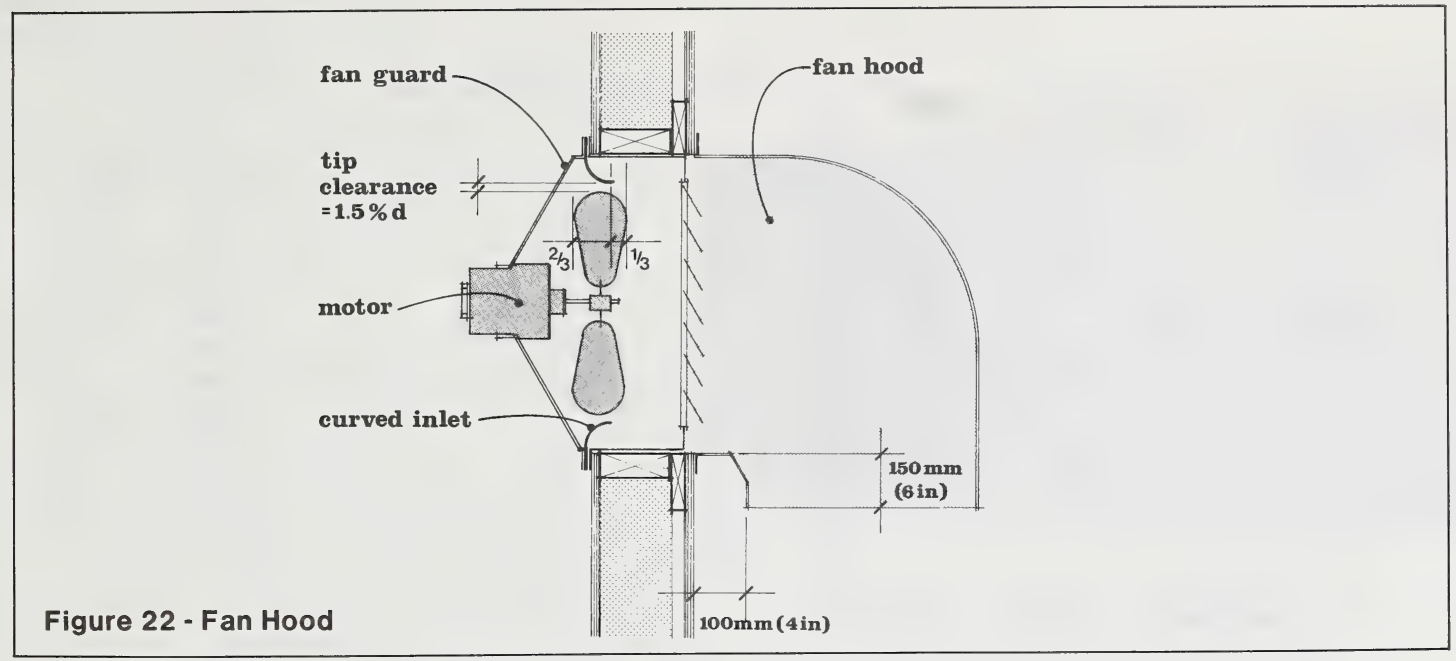

Inside this sphere the air moves towards the fan and increases in velocity as it approaches the fan.

Propeller fans are most common for ventilation in agricultural buildings. They are relatively inexpensive and exhibit high efficiency at low static pressures. Smaller fans may be direct driven. Larger fans are belt driven. Fans are available from many manufacturers as single speed, variable speed and belt driven models.

Fans function according to the basic fan laws as follows:

- Fan capacity is proportional to speed; the faster a fan is rotated, the more air it moves.

- Static pressure is proportional to the square of speed.

- Power required is proportional to the cube of speed. If a fan's speed is doubled, its power requirements increase 8 times.

Fans should have a shroud, or ring that fits closely around the blade. The shroud is, in effect, a bell shaped nozzle that improves a fan's efficiency as compared to a plain circular opening. Fans with no ring, or shroud, are suitable only for free air circulation. Shutters and hoods are used to reduce backdrafts and protect fans from the effects of winds.

Normally fans are located in the top $1 / 3$ of the wall. They may be banked, with banks spaced no greater than twice the building width, or they may be spaced evenly along the length of the barn. Fans may be on one side (narrow barns), or both sides (wide barns), of the building.

Controls for fans should be located near the centre of the building at eye level; sensors should be located at pig level. For single and two-speed fans, thermostats are used, and variable speed fans are controlled by a variable speed controller. This controller can run a motor load of up to $0.75 \mathrm{~kW}$. Each fan is then individually switched.
Controls must be kept free of dust and located in moving air. A mercury thermometer should be placed near the controls to sense barn temperature. Always verify the control setting with a thermometer.

Thermostats are seldom accurate when they arrive from the factory and should be calibrated after they are installed. A maximum-minimum thermometer placed at various locations around the barn is useful to calibrate controls.

Fans are chosen according to the air movement required for the barn. Table 6 gives capacities of some common agricultural fans. Table 7 gives ventilation requirements for pigs.

A wide choice of agricultural fans is available. These include single speed, two speed, multiple speed, and variable speed fans. The fan housing may be constructed of a variety of materials including fibreglass, stainless steel, galvanized metal and painted metal. Single speed fans are common. A single speed motor is used and its cost is relatively low. A combination of fans and controls is used to obtain the desired range of ventilation rates.

Two-speed fans use two-speed motors for an additional step in the range of ventilation rates. Most two-speed fans have a capacity at low speeds of $1 / 2$ to $2 / 3$ of their high speed capacity. Two-speed fans are used when it is not possible to obtain the desired ventilation rates using single speed fans.

Variable speed fans use variable speed motors. A solid state controller varies the motor speed from about 300 rpm to its maximum rated speed.

Variable speed fans will have a maximum rating near that of a single speed fan of the same size. The minimum capacity of variable speed fans is approximately $20 \%$ of their maximum capacity. Variable speed fans are used for ventilating livestock buildings with a small or variable amount of animal heat available.

Fans may also be direct drive or belt driven. Large fans, over $600 \mathrm{~mm}$ ( $24 \mathrm{in}$.) are usually belt driven at a slow 
TABLE 6 - TYPICAL CAPACITIES OF COMMON AGRICULTURAL FANS

\begin{tabular}{|c|c|c|c|c|}
\hline \multirow[t]{2}{*}{ Blade Diameter } & \multicolumn{2}{|c|}{$\begin{array}{c}\text { Capacity } \\
\text { Low Speed }\end{array}$} & \multicolumn{2}{|c|}{$\begin{array}{c}\text { Capacity } \\
\text { High or Single }\end{array}$} \\
\hline & $\mathrm{L} / \mathrm{s}$ & CFM & $L / s$ & CFM \\
\hline $200 \mathrm{~mm} \quad\left(8^{\prime \prime}\right)$ & 一 & - & 150 & (350) \\
\hline $250 \mathrm{~mm}\left(10^{\prime \prime}\right)$ & - & 一 & 250 & $(500)$ \\
\hline 300 mm (12") & 280 & $(600)$ & 600 & (1250) \\
\hline 350 mm (14") & 380 & $(800)$ & 800 & (1750) \\
\hline 400 mm (16") & 730 & $(1500)$ & 1200 & $(2500)$ \\
\hline 450 mm (18") & 850 & $(1800)$ & 1600 & $(3300)$ \\
\hline 500 mm (20") & 1180 & $(2500)$ & 2000 & $(4300)$ \\
\hline 600 mm (24") & 1420 & $(3000)$ & 2400 & $(5000)$ \\
\hline $900 \mathrm{~mm}\left(36^{\prime \prime}\right)$ & 2360 & $(5000)$ & 4800 & $(10000)$ \\
\hline
\end{tabular}

TABLE 7 - VENTILATION RATES FOR SWINE BARNS*

\begin{tabular}{|c|c|c|c|c|c|}
\hline Animal Type & Housing Type & $\begin{array}{l}\text { Continuous } \\
\text { Vent. Rate }\end{array}$ & $\begin{array}{c}\text { Moisture } \\
\text { Control Vent. } \\
\text { Rate }\end{array}$ & $\begin{array}{c}\text { Temperature } \\
\text { Control Vent. } \\
\text { Rate }\end{array}$ & $\begin{array}{l}\text { Maximum } \\
\text { Vent. Rate }\end{array}$ \\
\hline \multirow[t]{2}{*}{ dry sow } & $\begin{array}{l}\text { year round housing in } \\
\text { windowless barn }\end{array}$ & $5 \mathrm{~L} / \mathrm{s}$ & $5 \mathrm{~L} / \mathrm{s}$ & $65 \mathrm{~L} / \mathrm{s}$ & $75 \mathrm{~L} / \mathrm{s} / \mathrm{sow}$ \\
\hline & & $10 \mathrm{cfm}$ & $10 \mathrm{cfm}$ & $130 \mathrm{cfm}$ & $150 \mathrm{cfm}$ \\
\hline \multirow[t]{2}{*}{ sow \& litter } & $\begin{array}{l}\text { farrowing barn-year } \\
\text { round insulated housing }\end{array}$ & $7 \mathrm{~L} / \mathrm{s}$ & $7 \mathrm{~L} / \mathrm{s}$ & $125 \mathrm{~L} / \mathrm{s}$ & \\
\hline & & $15 \mathrm{cfm}$ & $15 \mathrm{cfm}$ & $250 \mathrm{cfm}$ & $280 \mathrm{cfm}$ \\
\hline \multirow{2}{*}{$\begin{array}{l}\text { weanlings } \\
\text { ( } 7 \text { to } 25 \mathrm{~kg} \text { ) }\end{array}$} & insulated weaner barn & $1 \mathrm{~L} / \mathrm{s}$ & $1 \mathrm{~L} / \mathrm{s}$ & $15 \mathrm{~L} / \mathrm{s}$ & $15 \mathrm{~L} / \mathrm{s} /$ pig \\
\hline & & $2 \mathrm{cfm}$ & $2 \mathrm{cfm}$ & $30 \mathrm{cfm}$ & $30 \mathrm{cfm}$ \\
\hline \multirow{4}{*}{$\begin{array}{l}\text { growers } \\
(25-60 \mathrm{~kg})\end{array}$} & insulated grower barn & $1 \mathrm{~L} / \mathrm{s}$ & $1 \mathrm{~L} / \mathrm{s}$ & $20 \mathrm{~L} / \mathrm{s}$ & $28 \mathrm{~L} / \mathrm{s} /$ grower \\
\hline & & $2 \mathrm{cfm}$ & $2 \mathrm{cfm}$ & $40 \mathrm{cfm}$ & $45 \mathrm{cfm}$ \\
\hline & $\begin{array}{l}\text { high density } \\
\left(0.7 \mathrm{~m}^{2} / \text { animal or less }\right)\end{array}$ & $2 \mathrm{~L} / \mathrm{s}$ & $2 \mathrm{~L} / \mathrm{s}$ & $30 \mathrm{~L} / \mathrm{s}$ & \\
\hline & & $4 \mathrm{cfm}$ & $4 \mathrm{cfm}$ & $60 \mathrm{cfm}$ & $60-80 \mathrm{cfm}$ \\
\hline \multirow[t]{4}{*}{$\begin{array}{l}\text { finishers } \\
(60-100 \mathrm{~kg})\end{array}$} & $\begin{array}{l}\text { lower density } \\
\left(0.7 \mathrm{~m}^{2} / \text { animal or more }\right)\end{array}$ & $2 \mathrm{~L} / \mathrm{s}$ & $2 \mathrm{~L} / \mathrm{s}$ & $30 \mathrm{~L} / \mathrm{s}$ & $30-40 \mathrm{~L} / \mathrm{s} / \mathrm{pig}$ \\
\hline & & $4 \mathrm{cfm}$ & $4 \mathrm{cfm}$ & $60 \mathrm{cfm}$ & $60-80 \mathrm{cfm}$ \\
\hline & $\begin{array}{l}\text { high density ( } 0.7 \\
\mathrm{~m}^{2} / \text { animal or less) }\end{array}$ & $2 \mathrm{~L} / \mathrm{s}$ & $2 \mathrm{~L} / \mathrm{s}$ & $25 \mathrm{~L} / \mathrm{s}$ & $30 \mathrm{~L} / \mathrm{s} /$ pig \\
\hline & & $4 \mathrm{cfm}$ & $4 \mathrm{cfm}$ & $50 \mathrm{cfm}$ & $60 \mathrm{cfm}$ \\
\hline \multirow{2}{*}{$\begin{array}{l}\text { growing } \\
\text { finishing } \\
\text { ( } 55 \mathrm{~kg} \text { avg) }\end{array}$} & $\begin{array}{l}\text { lower density } \\
0.7 \mathrm{~m}^{2} / \text { animal or more }\end{array}$ & $2 \mathrm{~L} / \mathrm{s}$ & $2 \mathrm{~L} / \mathrm{s}$ & $20 \mathrm{~L} / \mathrm{s}$ & 25-30 L/s/pig \\
\hline & & $4 \mathrm{cfm}$ & $4 \mathrm{cfm}$ & $40 \mathrm{cfm}$ & $50-60 \mathrm{cfm}$ \\
\hline
\end{tabular}


speed to reduce fan noise. The following are guidelines for selection and operation of fans:

1. Fan motors should be totally enclosed and have thermal overload protection.

2. Owing to capacity variations, select a fan on the basis of its capacity in litres per second (cubic feet per minute).

3. Capacity rating should be based on $3 \mathrm{~mm}$ (1/8 in.) of static pressure.

4. Install adequate wiring.

5. Fans should be hooded and equipped with gravity shutters to prevent backdrafts when the fans are stopped. Gravity shutters, or louvers, should not be used on continuously operating fans.

6. Fans, fan motors, and thermostats need to be regularly serviced. Dust buildup on fan blades and louvers can reduce fan discharge by up to $30 \%$. This has the effect of making an otherwise adequate ventilation system inadequate because of reduced air flow. Dust also reduces motor life by overheating and fan blade imbalance.

\section{PRESSURIZED VENTILATION SYSTEM}

Pressurized ventilation systems are sometimes used to ventilate hog barns. They function by forcing fresh air into the barn. Air is distributed within the barn by a duct. Stale air exits through louvers or exhaust ports. Most systems also have provision for blending fresh and recirculated air for better temperature control.

A tightly sealed vapor barrier is necessary to prevent warm moist air from entering the wall cavity and forming frost, condensation, or ice. This moisture reduces the insulation value and may cause deterioration of the structural members of the building. During winter operation, ice may form around any opening where warm moist air leaves the barn. This can occur around doors creating a problem.

Air quantities for pressure ventilation systems may be calculated in the same manner as for exhaust systems.

Polyethylene distribution ducts may be used with either a negative or positive pressure ventilation system. They are normally sized to give a velocity of 4 to $6 \mathrm{~m} / \mathrm{s}$ in the duct. Holes are spaced at intervals along the tube. The area of the holes should be 1.5 times the cross-sectional area of the tube. When the holes are not sized and spaced properly the plastic duct will vibrate. If these vibrations are allowed to continue the duct will tear. Polyethylene tubes tend to collect dust and need frequent maintenance. Figure 23 shows polyethylene distribution ducts used to distribute air in a pressure ventilated hog barn.

\section{NATURAL VENTILATION}

It is a well known fact that hot air rises. Natural ventilation systems make use of this principle and the effects of airflow caused by wind.

Air in the hog barn is heated by the animal's body heat and by supplementary heat added to maintain the barn

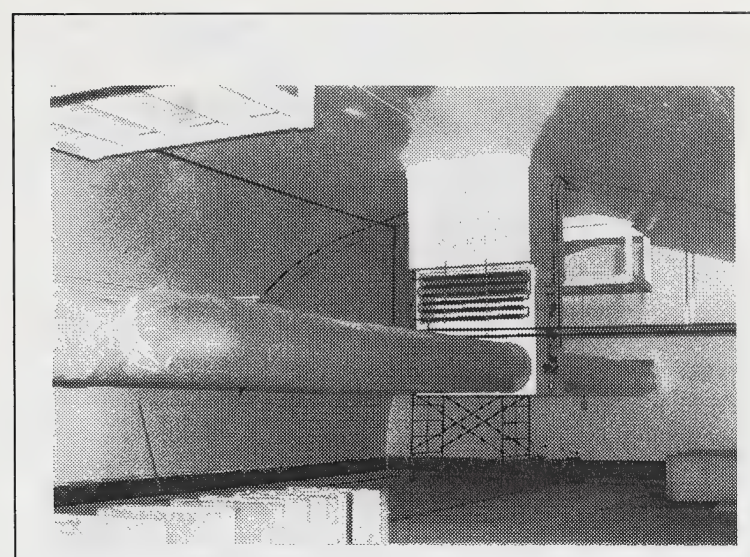

Figure 23 - Mixing Chamber System

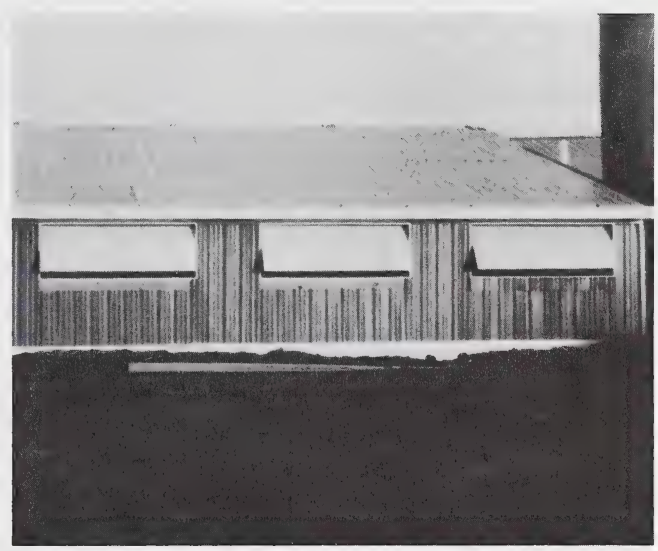

Figure 24 - Naturally ventilated hog barn

temperature. This heated air rises. If there is an opening at an upper level in the barn the warm, lighter air will leave the building. Of course, an equal volume of cold air must enter at a lower level.

Wind blowing against a building creates areas of high and low pressure. Where there are openings in the building these pressures create air flow into or out of the building.

By harnessing these two effects, thermal buoyancy and wind, air can be moved into and out of a building to ventilate it.

Problems arise in controlling the inlets and outlets in a naturally ventilated building. Typically a ridge opening is used as an outlet and movable wall panels are used as inlets. Changes in temperature or wind velocity necessitate adjustments to the system to control air flow rate. These adjustments can be made manually or by automatic control systems. Figure 24 shows a naturally ventilated hog feeder barn. 


\section{HEATING SYSTEMS FOR HOG BARNS}

Heat is required to maintain desired barn temperatures during periods of cold weather. Heat is also required to remove moisture from the interior of the building. This heat comes from two sources - animal body heat and supplemental heat. Radiant heat, usually generated by electrical energy, is used to modify local microenvironments such as creep areas. Radiant heat can be supplied by 250 watt infrared bulbs in an approved fixture, or the newer quartz tube radiant heaters. Temperatures are adjusted by raising or lowering the infrared heat source until the pigs are comfortable. A heat lamp and holder are shown in Figure 25.

Hot water heating is used to supply heat to the air space in the building and to heat concrete floors.

A typical hot water heating system consists of:

1. Hot water boiler sized to barn requirements.

2. Circulating pump; sold as part of boiler package.

3. Expansion tank

4. Distribution piping and headers

5. Heat distribution system, normally $50 \mathrm{~mm}$ (2 in.) black iron pipe for space heat, and plastic pipe for floor heat.

6. Controls, valves, temperature and pressure gauges, air bleed valves, pressure relief valve.

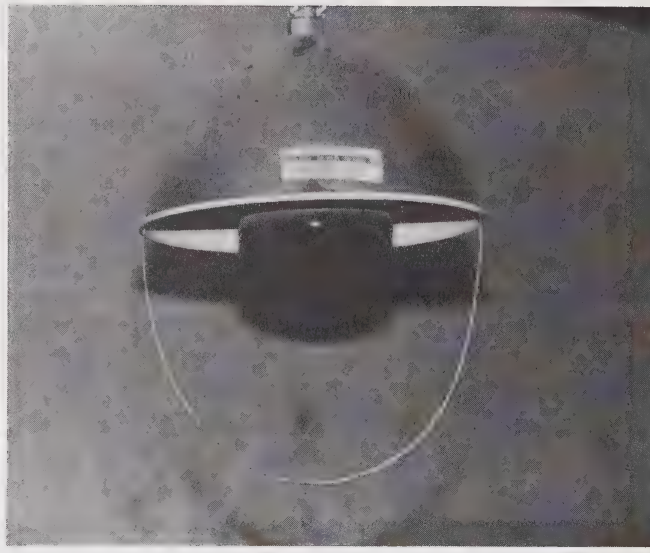

Figure 25 - Heat lamp and holder

The boiler should be located in a separate, fire resistant furnace room. The furnace room should be lined with a fire resistant material, such as gypsum board and have a separate outside entrance, equipped with a self-closing door. Vents to the outside are needed to provide combustion air for the furnace. All furnace installations require a permit and must meet Department of Labour standards. Figure 26 shows the layout of a typical hot water space heating system.

Boilers are normally operated at $90^{\circ} \mathrm{C}$ for space heat. Plastic pipe used for floor heat should not be exposed to water temperatures above $55^{\circ} \mathrm{C}$. Water temperature to the floor heating system can be supplied by a separate $55^{\circ} \mathrm{C}$ water source, or a thermostatically controlled blending valve for the floor heating circuit.

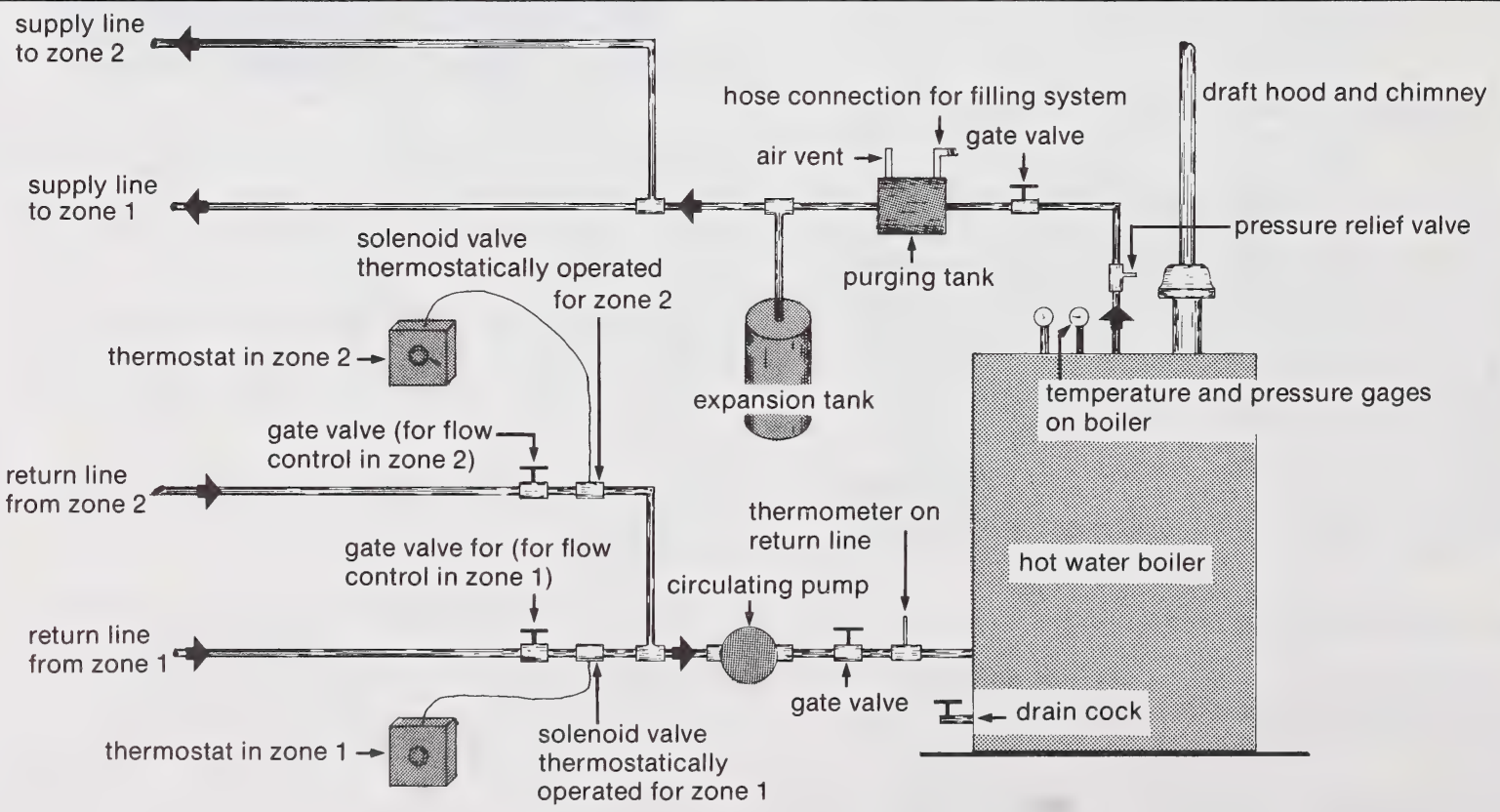

Figure 26 - Hot water space heating system serving two zones 
Black iron pipe, $50 \mathrm{~mm}$ ( $2 \mathrm{in}$.) in diameter, is used to distribute heat in the hog barn. It is located near the air inlets as shown in Figure 27.

Fan forced unit heaters are also used. Rooms, or locations where pipe can not be installed, can be heated by unit heaters (Figure 28).

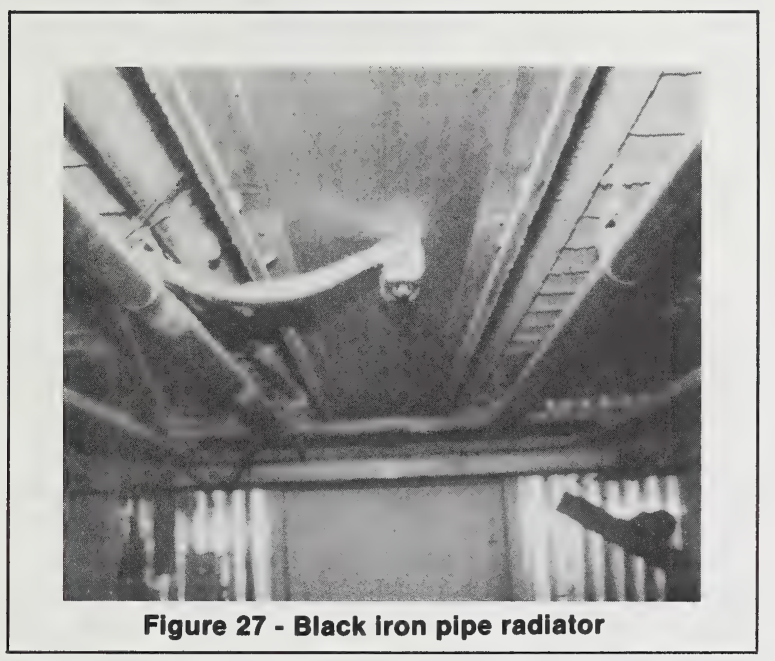

Zone valves and thermostats can be used to control temperatures in individual rooms in the barn.

Information in the following table can be used as a rough guide to estimate the size of the heating unit for a typical hog barn.

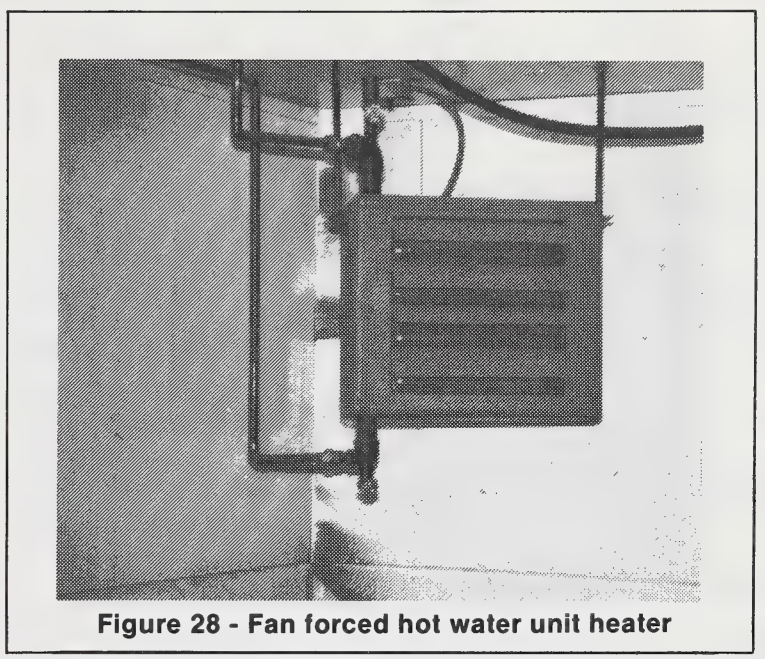

\section{TABLE 8 - APPROXIMATE HEAT REQUIREMENTS FOR SWINE BARNS}

Finishing Barn

Farrowing Barn

Weaner Barns

raised decks

floor pens

Dry Sow Barn
800 watts/metre of building length

2000 watts/crate

2300 watts/deck

1200 watts/metre of building length

800 watts/metre of building length

$800 \mathrm{Btu} / \mathrm{hr}-\mathrm{ft}$
$6000 \mathrm{Btu} / \mathrm{crate}$
$7000 \mathrm{Btu} / \mathrm{deck}$
$1200 \mathrm{Btu} / \mathrm{hr}-\mathrm{ft}$
$800 \mathrm{Btu} / \mathrm{hr}-\mathrm{ft}$

$800 \mathrm{Btu} / \mathrm{hr}-\mathrm{ft}$

$800 \mathrm{Btu} / \mathrm{hr}-\mathrm{ft}$

\section{FLOOR HEATING SYSTEMS}

Floor heating systems are used to provide a warm environment for the pigs without excessive heating of the entire building. Floor heat is an excellent way to provide extra heat in creep areas. It is a convenient method of providing a warm, dry sleeping area in grower-finisher pens.

Do not expect floor heat to provide all of the heat needed in the building. Floor heat will not be sufficient for the proper operation of the ventilation system. Supplemental space heat will be required, especially in farrowing and weaning areas.

Floor heating does have some disadvantages, however. It increases the cost and difficulty of construction of a swine barn and it requires additional management and maintenance once the system is in place. Also, raised farrowing crates and flat decks do not lend themselves to floor heat.

Two options are available to heat the floor slab: either electric heat tape, placed in the concrete, or hot water piping buried beneath the floor slab. Electric systems are more flexible in that individual pens can be individually temperature controlled. However, electricity is a relatively expensive method of providing heat. Hot water systems do not readily lend themselves to the temperature control of individual pens.

Floor heat should be installed only under the pig's resting area. It should not be placed under parts of the pen that are normally wet, such as waterers and the dunging area. Floor heat should never be placed under a sow in a farrowing pen, as it may lead to udder problems. 


\begin{tabular}{|c|c|c|c|c|}
\hline Pig Size & Heated Floor Area & Watts $/ \mathrm{m}^{2}$ & $\begin{array}{l}\text { Recommended Floor } \\
\text { Temperatures } \\
\end{array}$ & Location of Heated Floor \\
\hline $\begin{array}{l}\text { Birth to } \\
\text { Weaning }\end{array}$ & 0.5 to $1.4 \mathrm{~m}^{2} /$ litter & 120 & $\begin{array}{l}35^{\circ} \mathrm{C} \text { dropping to } 24^{\circ} \mathrm{C} \\
\text { by } 3-4 \text { weeks }\end{array}$ & $\begin{array}{l}1 \text { creep of a side creep } \\
\text { farrowing crate or front creep of } \\
\text { a farrowing crate }\end{array}$ \\
\hline $\begin{array}{l}\text { Weaning } \\
\text { to } 27 \mathrm{~kg}\end{array}$ & 0.1 to $0.15 \mathrm{~m}^{2} / \mathrm{pig}$ & 80 & $21^{\circ} \mathrm{C}$ to $24^{\circ} \mathrm{C}$ & \\
\hline $\begin{array}{l}27 \text { to } 57 \\
\mathrm{~kg}\end{array}$ & 0.2 to $0.24 \mathrm{~m}^{2} / \mathrm{pig}$ & 80 & $16^{\circ} \mathrm{C}$ to $21^{\circ} \mathrm{C}$ & $\begin{array}{l}1250 \mathrm{~mm} \text { at the front of a } 1500 \times \\
4800 \mathrm{~mm} \text { pen }\end{array}$ \\
\hline $\begin{array}{l}57 \mathrm{~kg} \text { to } \\
\text { Market }\end{array}$ & 0.3 to $0.33 \mathrm{~m}^{2} / \mathrm{pig}$ & 60 & $16^{\circ} \mathrm{C}$ & \\
\hline
\end{tabular}

Too large a heated floor area wastes heat and too small an area encourages pigs to pile up. Table 9 gives guidelines for heated floor area and floor temperatures.

\section{HOT WATER FLOOR HEAT}

Equipment needed to install floor heat includes a hot water heater or boiler (depending on the size of the installation), expansion tank, a circulating pump, and steel piping above the floor and plastic line beneath the floor area to be heated. Alternatively a mixing valve or converter can be used to supply hot water at the desired temperature to the system. In addition, pressure and temperature gauges, control valves and pressure relief valves will be required. Polyethylene lines may be used beneath the floor pad to be heated. Use only $760 \mathrm{kPa}$ CSA approved polyethylene water line or high density polyethylene water line.

Hot water pipes are placed on a layer of sand on a compacted gravel fill. The system is laid out, all connections made, then it is pressure tested for leaks. Next, a layer of sand is placed around the pipes and the concrete poured.

As a general guide pipes are spaced $200 \mathrm{~mm}$ ( $8 \mathrm{in}$.) on centre beneath creep areas, $250 \mathrm{~mm}$ (10 in.) o.c. beneath weaner areas and $300 \mathrm{~mm}$ (12 in.) o.c. beneath grower pens. Either $19 \mathrm{~mm}$ or $25 \mathrm{~mm}$ (3/4 in. or $1 \mathrm{in}$.) pipe may be used. If the pipe loop is less than $60 \mathrm{~m} \mathrm{(200}$ $\mathrm{ft}$ ), $19 \mathrm{~mm}$ ( $3 / 4 \mathrm{in}$.) pipe may be used. If a pipe loop is 60 $\mathrm{m}$ to $80 \mathrm{~m}$ (200 ft to $250 \mathrm{ft}$ ), $25 \mathrm{~mm}$ ( $1 \mathrm{in}$.) pipe is suitable. A pipe loop should not be longer than $80 \mathrm{~m}$ $(250 \mathrm{ft})$. Plastic pipe connections should not be made in the concrete. Water temperatures for a floor heating system using $760 \mathrm{kPa}$ (125 psi) pipe should not exceed $60^{\circ} \mathrm{C}$. Temperatures higher than this will cause the pipe to soften and weaken. High density pipe can withstand temperatures to $90^{\circ} \mathrm{C}$. In either case pressures in the system should not exceed $140 \mathrm{kPa}(20 \mathrm{psi})$. Table 10 gives floor temperatures for various pipe spacings and water temperatures. Table 11 gives desired floor temperatures for various classes of pigs.

Boiler or hot water tank output can be determined by the following general rule - supply 50 to 100 watts/meter of pipe (50 to $100 \mathrm{Btu}$ / foot per hour). Water temperature should be $60^{\circ} \mathrm{C}$ temperature drop from supply to return. Circulation pump capacity should be 1.5 litres / $\mathrm{min}$ for each 1000 watts of boiler capacity ( $1 \mathrm{gal} / \mathrm{min}$ per 10,000 Btu). The expansion tank should hold $10 \%$ of the volume of water in the system.

Floor temperature can be sensed and used to control a

\section{TABLE 10 - FLOOR TEMPERATURES ACHIEVED WITH VARIOUS PIPE SPACINGS AND WATER TEMPERATURES (Note: pipe is $25 \mathrm{~mm}$ )}

\begin{tabular}{ccr}
\hline Floor Temperature & Water Temperature & Pipe Spacing \\
& & \\
$32^{\circ} \mathrm{C}$ & $55^{\circ} \mathrm{C}$ & $185-200 \mathrm{~mm}$ \\
$29^{\circ} \mathrm{C}$ & $51^{\circ} \mathrm{C}$ & $200-225 \mathrm{~mm}$ \\
$28^{\circ} \mathrm{C}$ & $38^{\circ} \mathrm{C}$ & $300-375 \mathrm{~mm}$ \\
$26^{\circ} \mathrm{C}$ & $46^{\circ} \mathrm{C}$ & $225-250 \mathrm{~mm}$ \\
$23^{\circ} \mathrm{C}$ & $42^{\circ} \mathrm{C}$ & $250-300 \mathrm{~mm}$
\end{tabular}




\section{Weight or Age}

Birth to Weaning

Weaning to $25 \mathrm{~kg}$

$25 \mathrm{~kg}$ to $60 \mathrm{~kg}$

$60 \mathrm{~kg}$ to Market
Desired Floor Temperature $\left({ }^{\circ} \mathrm{C}\right)$

24-35

21-24

16-21

10-20 solenoid, or zone control valve to control floor temperature. This is done by placing a metal conduit with a closed end and large radius bend in the concrete. It is located 100 to $150 \mathrm{~mm}$ (4 to 6 in.) from any heating pipe. A thermostat with capillary tube and sensing bulb is used. The sensing bulb and capillary tube are placed in the conduit which is then filled with a light oil. The thermostat senses floor temperature and controls water flow by turning the solenoid valve off or on. A typical hot water floor heating system is shown in Figure 29. Figures 30 and 31 show pipe layout for creep heating.

Normally 2 to 3 days are required to warm up the concrete or allow it to cool down because of its heat holding capacity. This has management implications. In order to have the floor up to temperature it will be necessary to start the system 2 to 3 days before the heated floor is needed.

$760 \mathrm{kPa}-19 \mathrm{~mm}$ polyethylene pipe under floor at $400 \mathrm{~mm}$ on centre

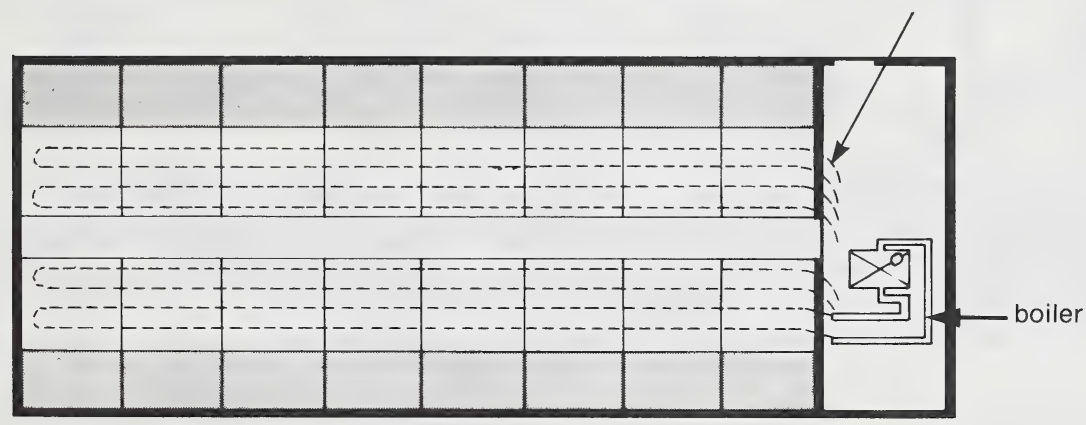

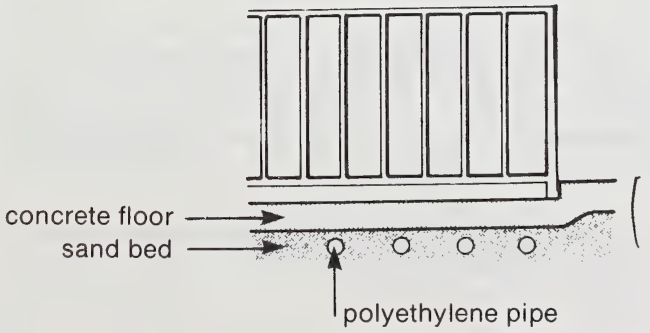

Figure 29 - Typical hot water floor heat system

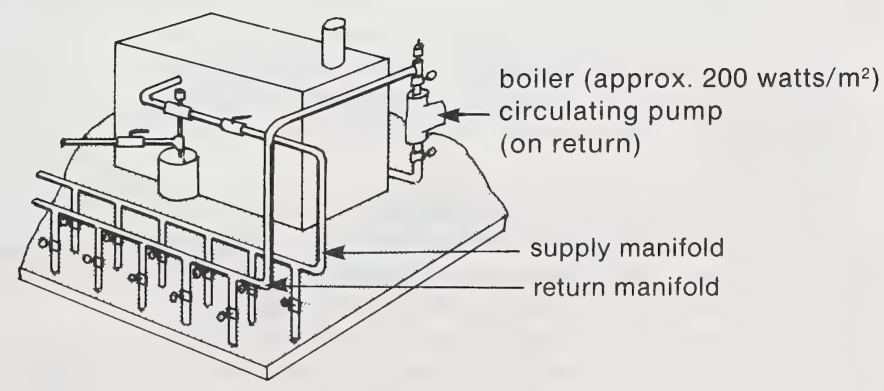




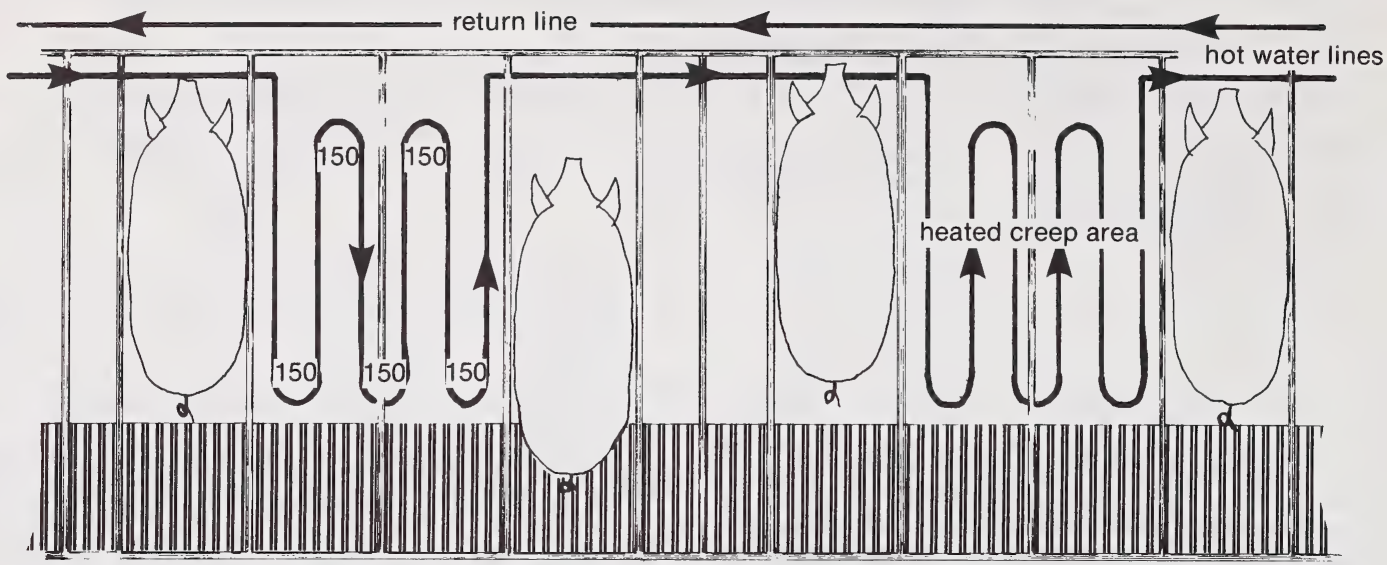

Figure 30 - Pipe layout to provide heated floor in creep area of farrowing crate with side creeps (Note: no heated floor under sows). Spacing is $150 \mathrm{~mm}$ in the creep area.

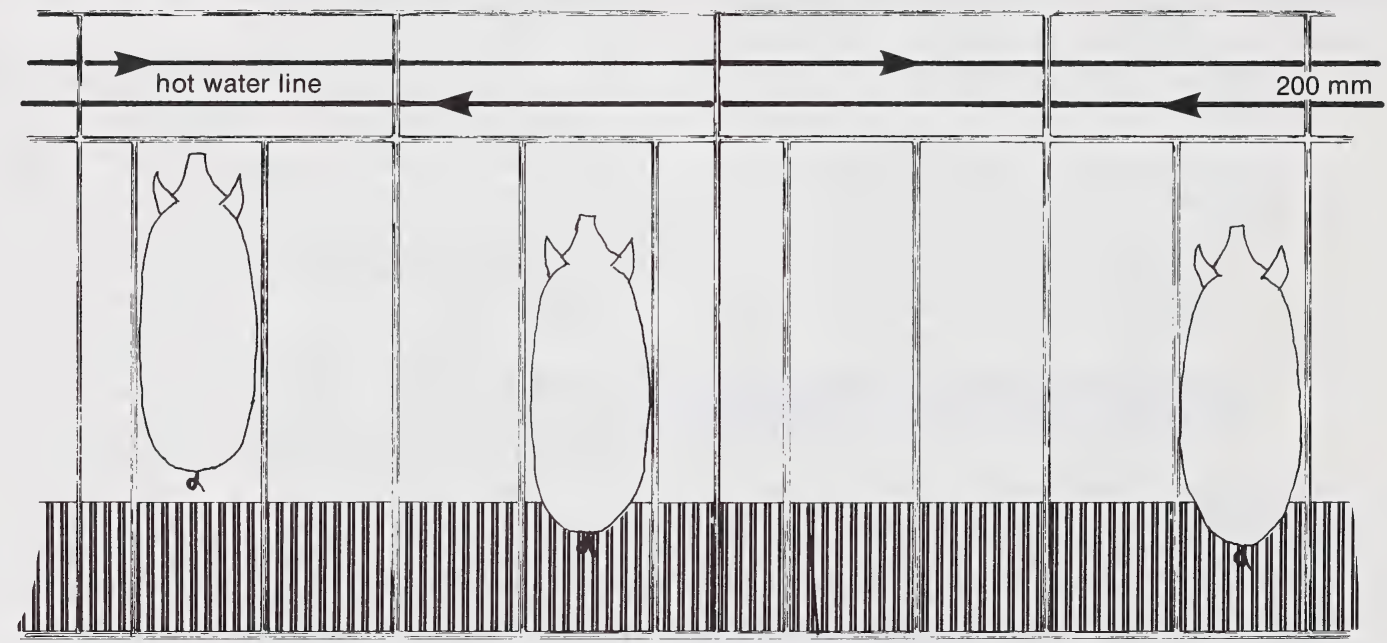

Figure 31 - Pipe layout to provide heated floor in front creep area of farrowing crate with front creep

\section{ELECTRIC FLOOR HEAT}

A polyvinyl chloride covered electric heat tape can be used for floor heat. Alternatively, prefabricated electric heat pads of various sizes can be used. Table 12 shows cable spacing at various watt densities and watts per metre of cable.

Your own heating pads can be fabricated with a plywood jig that will fit a normal creep area or the front of a pen. Place nails at the end of the jig to provide the necessary watt density and lay the cable in the desired pattern. Enough lead-in wire must be left to allow for threading through a conduit to a switch. Slip the unit off the jig and transfer to a sheet of cement-asbestos board. Tape the wires to the cement-asbestos board and place in the floor as outlined below:

- Place $150 \mathrm{~mm}$ (6 in.) of compacted gravel fill over the entire floor area and cover with a $0.1 \mathrm{~mm}$ (4 mil) vapor barrier.
- Place $50 \mathrm{~mm}$ (2 in.) of rigid foam insulation over the areas to be heated.

- Place $65 \mathrm{~mm}$ (2.5 in.) of concrete over the insulation and vapor barrier.

- Place the heating mat, conduit for lead-in wires, and the conduit (with sealed end) for thermostatic control.

- Place $40 \mathrm{~mm}$ (1.5 in.) of concrete over the cable and conduit.

For effective temperature control a separate thermostat should be used for every 3-5 crates and for every zone in the weaner and feeder barns.

The cable should be turned on one day before the heated floor area is needed. Figure 32 shows a typical installation. 
TABLE 12 - CABLE SPACING FOR HEATING FLOOR SLABS

\begin{tabular}{crrrrrr}
\hline & \multicolumn{6}{c}{ WATTS/LINEAL METRE OF HEATING CABLE } \\
WATT DENSITY & 33 & \multicolumn{7}{c}{36} & 40 & 43 & 46 & 50 \\
\cline { 2 - 6 } W/m & \multicolumn{7}{c}{ SPACING BETWEEN RUNS OF CABLE (mm) } \\
\cline { 2 - 6 } & 120 & 130 & 140 & 150 & 170 & 180 \\
250 & 100 & 110 & 120 & 130 & 140 & 150 \\
300 & 85 & 95 & 100 & 110 & 120 & 130 \\
350 & 80 & 80 & 90 & 100 & 110 & 110 \\
400 & & & & & \\
\end{tabular}

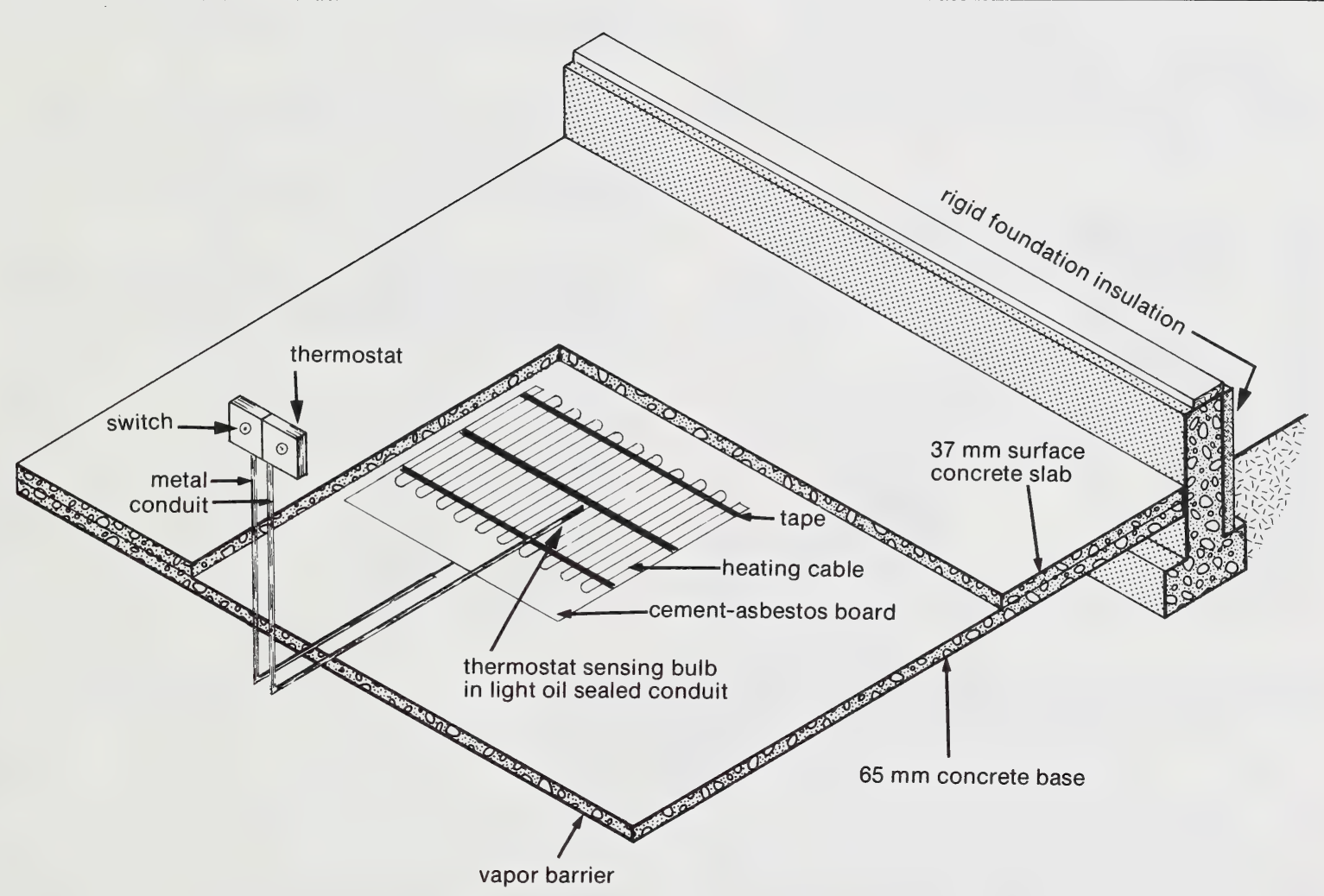

Figure 32 - Typical electric heat pad installation

Before installing electrically heated floor pads check that your service panel can handle the load. In addition, remember that electricity is a relatively expensive form of heat energy. 


\section{WATER SUPPLY}

Water is the most essential nutrient for pig production. Water consumption will vary with size of pig, environmental factors, and the salt content of both feed and water. Limiting water will affect the performance of all types of pigs.

\section{WATER QUALITY}

Pigs will consume 2 to $2.5 \mathrm{~L}$ of water per kg of dry feed. Under high temperature conditions pigs will consume up to 4.5 litres of water per kg of dry feed. When planning your hog barn, the water supply should provide 20 litres of water per day per sow housed, 7 litres/day/feeder pig housed and 3 litres/day/weaner pig housed. Additional water will be needed for washing pens and equipment.

Pigs require clean potable water. Total solids content up to $7000 \mathrm{mg} / \mathrm{L}$ is acceptable for growing pigs. Table 13 outlines water quality based on total dissolved solids.

\section{TABLE 13- WATER QUALITY}

$\begin{array}{ll}\text { TOTAL SOLIDS CONTENT OF WATER }(\mathrm{mg} / \mathrm{L}) \\ \text { TDS } & \text { QUALITY } \\ 0-999 & \text { Excellent } \\ 1000-3999 & \text { Good } \\ 4000-6999 & \text { Satisfactory } \\ 7000+ & \text { Unsatisfactory }\end{array}$

Some concern has been expressed when using water high in TDS for lactating sows. With this in mind 5000 $\mathrm{mg} / \mathrm{L}$ has been set as the upper limit for lactating sows.

Nitrates and sulphates are problem salts in some waters. Nitrates in livestock water are often an indication of bacterial contamination. Bacterial contamination of the water and conversion of nitrate to nitrite can cause problems with pigs. High levels of sulphate will cause the pigs to have a mild diarrhea, although performance is usually not affected. Young pigs can not tolerate a high level of sulphate.

\section{WATERING EQUIPMENT}

Several types of pig waterers are available. Many factors must be evaluated prior to purchasing waterers. First, what is your water supply? Some drinker types operate only with a low pressure, others operate from high pressure. Drinkers operating with low pressure require a header tank or pressure reducing valves. Is the water supply free of debris? If not, a filter should be installed.
20 pigs per waterer and a minimum of one waterer per pen. In weaner pens use two waterers. This gives less aggressive pigs a better chance to obtain water. Locate the waterer in a corner area over the slatted floor portion of the pen. In farrowing crates provide two waterers - one that is easily accessible for the sow, and one for the piglets. Locate the waterer for the piglets at the rear of the farrowing crate.

Watering bowls have the advantage of providing an obvious water source. Two types of bowls are available - one has a nose activated paddle mechanism to release the water. The other has a float valve mechanism. Bowls need to be cleaned regularly so that they provide fresh, clean water. A disadvantage of water bowls is that the pigs tend to play with them and waste large quantities of water.

Several types of nipples are available. They should be mounted on a movable bracket and be easily adjusted. The ideal height of the nipple is $50 \mathrm{~mm}$ (2 in.) above the pig's back. Independent studies have shown that nipples waste less water than do bowls.

The watering system can be used to medicate the pigs. One advantage is that even a sick pig drinks. A manifold system can be used to install the medicator. 


\section{SIZING THE HOG BARN}

Many philosophies exist in regard to the sizing of a hog barn. Traditionally it has been based on the number of sows in the buildings herd. Tables 14 and 15 give space allocations for a variety of sow herd sizes, based on 4 and 5 week weaning respectively. Assumed in the tables is a 1 week cleanup and filling time for the farrowing facilities and an average of 8.5 pigs weaned per litter. As management practices significantly effect barn sizing these tables are presented to provide preliminary planning information.

Another approach is to base the barn size on farrowing per week. This is an excellent approach to use on sizing a multiple room facility. The number of rooms needed equals the number of weeks to weaning plus one.

Farrowing crates per room is equal to desired farrowing per week. Usually, in this style of barn individual weaner rooms are used, one per farrowing room. These rooms are sized based on the number of farrowing crates. A typical sizing is one $1200 \times 2400 \mathrm{~mm}$ weaner deck per two farrowing crates, however, this is slightly undersized for superior production.
TABLE 14 - HOG BARN SIZING

\begin{tabular}{rrr}
\hline Sows & Crates & Sow Stalls \\
& & \\
20 & 5 & 16 \\
30 & 8 & 24 \\
40 & 10 & 32 \\
50 & 13 & 39 \\
60 & 15 & 47 \\
70 & 18 & 55 \\
80 & 21 & 63 \\
90 & 23 & 71 \\
100 & 26 & 79 \\
110 & 28 & 87 \\
120 & 31 & 95 \\
130 & 33 & 103 \\
140 & 36 & 111 \\
150 & 38 & 118 \\
200 & 51 & 158
\end{tabular}

8.5 pigs / litter

4 WEEK WEAN (4-5)

$\begin{array}{rrrrr}\begin{array}{r}\text { Gilt } \\ \text { Pens }\end{array} & \begin{array}{r}\text { Boar } \\ \text { Pens }\end{array} & \begin{array}{r}\text { Weaner } \\ \text { Pens }\end{array} & \begin{array}{r}\text { Grower } \\ \text { Pens }\end{array} & \begin{array}{r}\text { Feeder } \\ \text { Pens }\end{array} \\ 1 & & 3 & 2 & 13 \\ 2 & 1 & 5 & 3 & 19 \\ 3 & 2 & 7 & 4 & 25 \\ 3 & 3 & 9 & 5 & 31 \\ 4 & 3 & 10 & 6 & 38 \\ 5 & 4 & 12 & 7 & 44 \\ 5 & 5 & 14 & 8 & 50 \\ 6 & 5 & 15 & 9 & 57 \\ 7 & 6 & 17 & 10 & 63 \\ 8 & 7 & 19 & 11 & 69 \\ 8 & 7 & 20 & 12 & 75 \\ 9 & 8 & 22 & 13 & 82 \\ 10 & 9 & 24 & 14 & 94 \\ 10 & 9 & 26 & 15 & 126 \\ 14 & 10 & 34 & 20 & \end{array}$

\section{TABLE 15 - HOG BARN SIZING}

\section{5 pigs/litter 5 WEEK WEAN (5-6)}

\begin{tabular}{|c|c|c|c|c|c|c|c|}
\hline Sows & Crates & Sow Stalls & $\begin{array}{r}\text { Gilt } \\
\text { Pens }\end{array}$ & $\begin{array}{l}\text { Boar } \\
\text { Pens }\end{array}$ & $\begin{array}{r}\text { Weaner } \\
\text { Pens }\end{array}$ & $\begin{array}{r}\text { Grower } \\
\text { Pens }\end{array}$ & $\begin{array}{r}\text { Feeder } \\
\text { Pens }\end{array}$ \\
\hline 20 & 6 & 15 & 2 & 1 & 4 & 2 & 12 \\
\hline 30 & 9 & 23 & 2 & 2 & 6 & 3 & 18 \\
\hline 40 & 12 & 30 & 3 & 3 & 8 & 4 & 24 \\
\hline 50 & 14 & 38 & 4 & 3 & 10 & 5 & 30 \\
\hline 60 & 17 & 45 & 5 & 4 & 12 & 6 & 36 \\
\hline 70 & 20 & 53 & 5 & 5 & 13 & 7 & 42 \\
\hline 80 & 23 & 60 & 6 & 5 & 15 & 8 & 48 \\
\hline 90 & 26 & 68 & 7 & 6 & 17 & 8 & 54 \\
\hline 100 & 29 & 75 & 8 & 7 & 19 & 9 & 60 \\
\hline 110 & 32 & 83 & 8 & 7 & 21 & 10 & 66 \\
\hline 120 & 35 & 91 & 9 & 8 & 23 & 11 & 72 \\
\hline 130 & 38 & 98 & 10 & 9 & 25 & 12 & 78 \\
\hline 140 & 41 & 106 & 11 & 9 & 27 & 13 & 84 \\
\hline 150 & 43 & 113 & 12 & 10 & 29 & 14 & 90 \\
\hline 200 & 58 & 151 & 15 & 13 & 38 & 19 & 120 \\
\hline
\end{tabular}




\section{FARROWING HOUSING AND EQUIPMENT}

Newly born piglets are very vulnerable. Surveys have shown that $20-35 \%$ of liveborn pigs die before reaching market weight. Most of these deaths are caused by chilling of the newborn piglet and by the sow crushing the piglet. Many ways are available to crate or tether the sow and to provide safe comfortable creep areas for the piglets.

The major factors to be considered in planning farrowing accommodations are as follows:

- Welfare of the sow and piglets including cleanliness.

- Ease of observation and supervision.

- Labor economy (front creeps to improve piglet accessibility and slatted floors to achieve self cleaning).

- Minimize capital investment.

Today's trend in farrowing facilities is to multiple rooms and all in, all out production schedules. Sows are batch farrowed, and after the piglets are weaned, the farrowing room is depopulated and sanitized. It is then allowed to stand idle for a few days before the next group of sows is moved into the room.

\section{SOW WASH}

It makes no sense to clean farrowing pens then put dirty sows into them. Sows should be washed before entering farrowing facilities.

A simple sow wash is a small pen $1200 \times 2400(4 \mathrm{ft} \times 8$ $\mathrm{ft}$ ) with a floor drain and a warm water hose. The sow is hosed and scrubbed until she is clean.

Alternatively, a farrowing crate can be used as the wash stall. The lower horizontal rails on each side of the crate can be perforated and connected to the water supply.

Again a floor drain is provided.

Another alternative is to wash the sows in groups. A pen that allows $0.8 \mathrm{~m}^{2} / \mathrm{sow}\left(8.5 \mathrm{ft}^{2} / \mathrm{sow}\right)$ of space is equipped with nozzles and overhead nozzles to spray the sows with warm water. The nozzles deliver 10-15 litres per sow per hour at $30^{\circ} \mathrm{C}$. The pen is located in an enclosed corridor leading to the farrowing quarters.

\section{FARROWING CRATES}

Ideally a farrowing crate should:

\section{Reduce piglet crushing by:}

- controlling the movements of the sow within the pen.

- attracting piglets to a comfortable creep area.
- cater to the differing temperature requirements of sow and piglets by providing a higher temperature in the creep area.

\section{Ensure adequate nursing and suckling by:}

- ensuring that the bottom bars of the farrowing crate are high enough and the crate wide enough to ensure that these bars do not interfere with the piglets' suckling.

- providing a comfortable floor surface to encourage the sow to rotate her body at nursing to fully expose all teats on the lower udder to her piglets.

The farrowing crate should control the movements of the sow in such a way that she is forced to lie down on her belly before rolling over to either side. Most crushing of piglets occurs when sows flop on to either side from the standing position, trapping unsuspecting piglets.

Farrowing crates may have adjustable front and rear gates. In partially slatted pens an adjustable front gate helps move small sows and gilts back over the slotted portions. Some crates have adjustable sides and bottom bars. These are useful in adjusting the crate according to sow size. Lowering the adjustable bottom bar can prevent small sows being trapped underneath, while the lower bar can be raised for large sows allowing adequate access by the piglets to all the teats. Front access to the crate is useful and desirable, however, a rear access alley is essential. Access alleys should not be less than $750 \mathrm{~mm}$ (30 in.) in width.

The floor surface for the farrowing crate should:

- Eliminate risk of injury to piglets and the udder.

- Be comfortable to the sow and provide her with a good foothold.

- Be easy to clean.

- Be durable.

In some types of slatted flooring, hole size is too large for the piglets' feet. The gap should not exceed $10 \mathrm{~mm}$ (3/8 in.).

The creep area should provide a temperature of 28$30^{\circ} \mathrm{C}$. Front creeps are desirable, however, piglets must be trained to use them. For the first 24 hours provide a comfortable, attractive creep on each side of the sow, then make them less attractive (i.e. remove light and heat to front creep) and make the front creep more attractive. Crates with only side creeps can be equipped with a hover to provide a comfortable, warm environment for the piglets.

Farrowing crates may be placed at floor level or raised above it. Floor level crates usually have a double floor slope. The front $450 \mathrm{~mm}$ (18 in.) slopes towards a front drain at $5 \%$, the rear $1650 \mathrm{~mm}(6 \mathrm{ft})$ slopes to a rear gutter at $5 \%$. A smooth non-slip concrete floor is used beneath the crate. Hot water heat pipes are placed in 

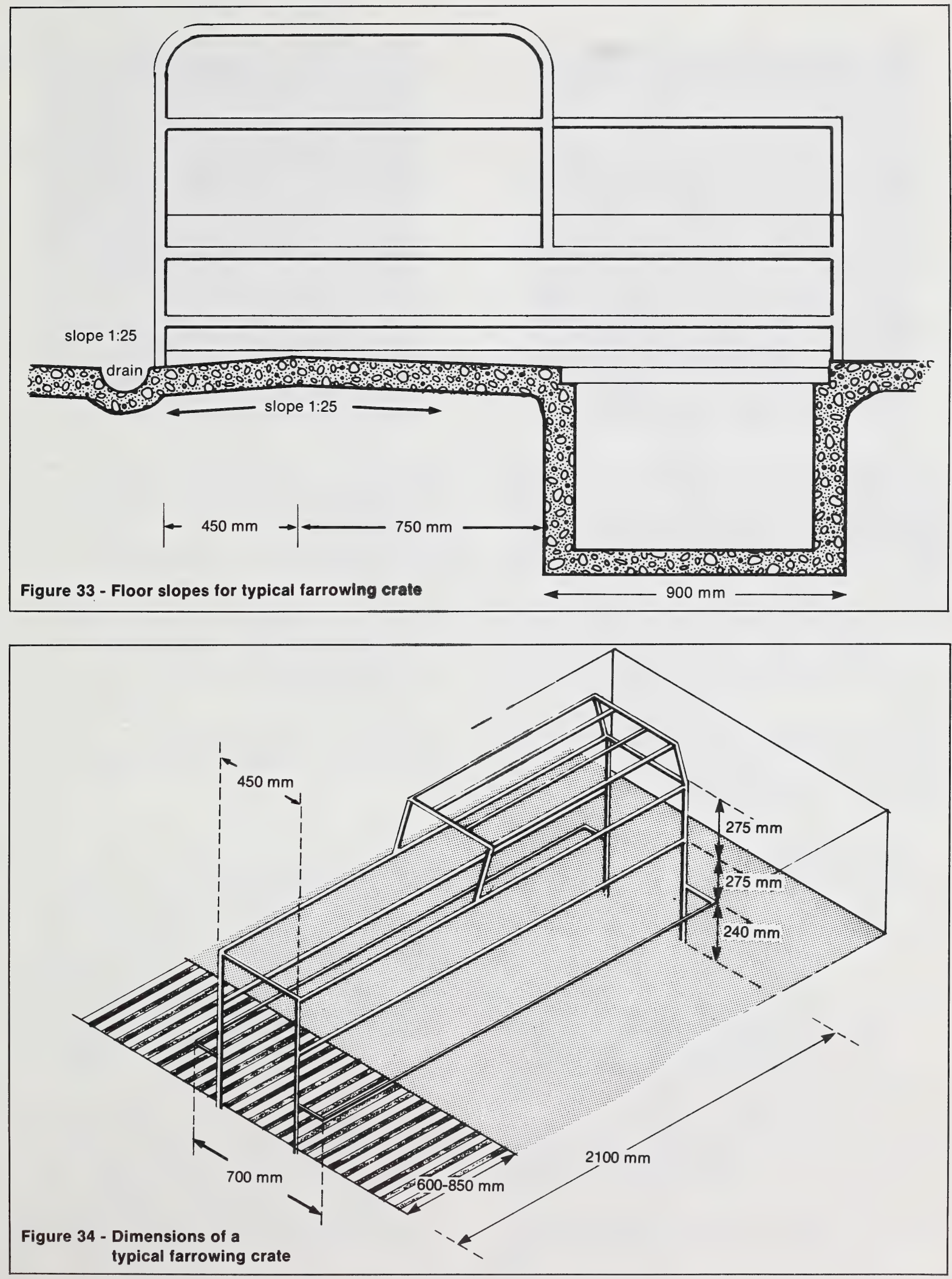


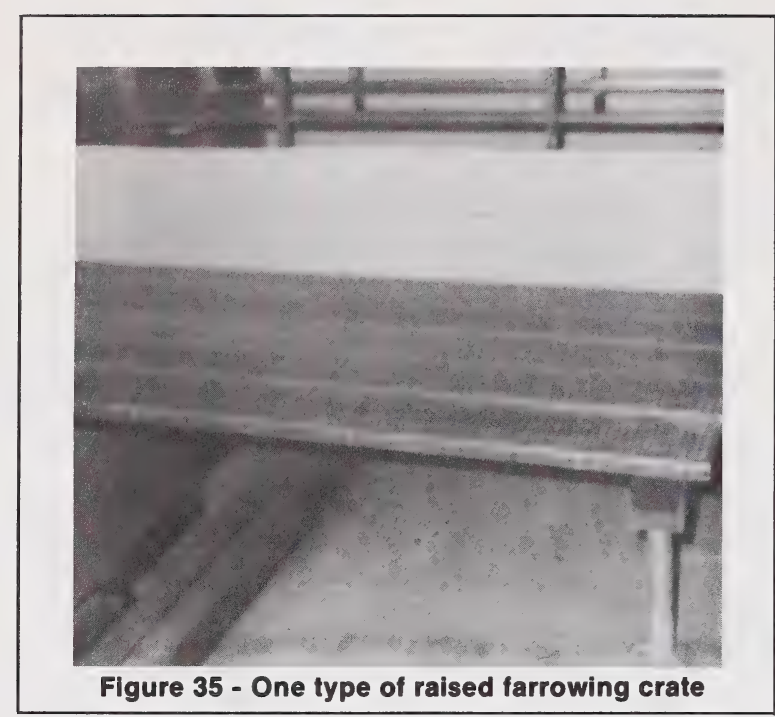

the concrete floor beneath the creep areas. No heat is placed beneath the sow. Figure 33 shows desired floor slope. Figure 34 shows dimensions of a typical farrowing crate. Figure 35 shows a raised farrowing crate, while Figure 36 shows a conventional farrowing crate.

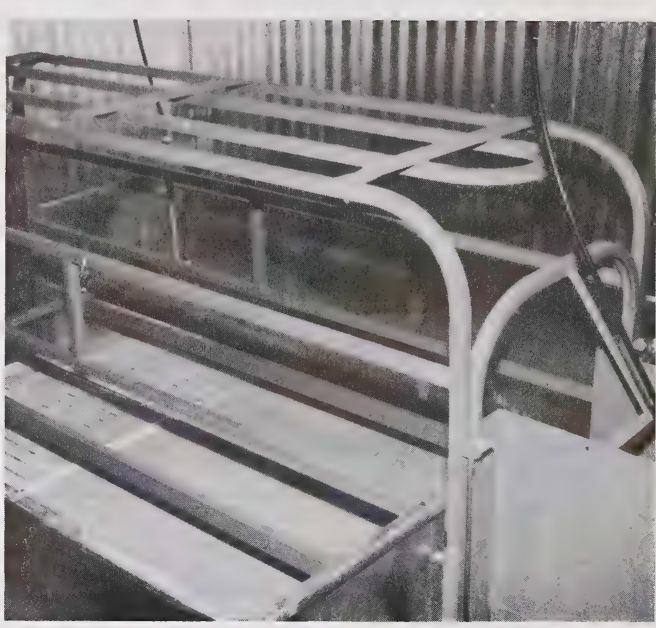

Figure 36 - Conventional floor level farrowing crate

Desirable environmental temperatures in the farrowing area are $21^{\circ} \mathrm{C}$ for the sow and $28-30^{\circ} \mathrm{C}$ for piglets dropping to $21-25^{\circ} \mathrm{C}$ by weaning. The room should be kept draft free.

Facilities that are using raised farrowing crates should be operated at $26^{\circ} \mathrm{C}$. 


\section{WEANER HOUSING AND EQUIPMENT}

After the pigs are weaned they are moved into the weaner area. Pigs are kept in the weaner area until they reach $25 \mathrm{~kg}(55 \mathrm{lb})$ in size. Many different facilities are used to produce weaner pigs, however, certain basic principles apply to all of them.

By keeping group size small and providing an optimal thermal environment, stress can be minimized. Pigs should be kept in groups of 20 pigs or less (2 litters) to minimize social stress. Temperatures to aim for are 27$29^{\circ} \mathrm{C}$ for the first week to 10 days after weaning and then dropping by $2-3^{\circ} \mathrm{C}$ per week to $21^{\circ} \mathrm{C}$ when the pigs are 9 weeks old.

Weaner housing that is easy to clean and easy to keep clean is essential. Presently the concept is to use weaner rooms and all-in, all-out production. A batch of pigs is weaned and a weaner room filled. This group of pigs is then removed and the room cleaned and disinfected prior to introducing the next group of pigs. Another consideration is the rapid removal of manure and urine. A totally perforated floor is useful in achieving this.

A good quality feed and a supply of good water are essential. Self-feeders can be used to provide feed. Feeders should be adjustable to minimize feed wastage. Nipple waterers provide fresh, clean water with a minimum of spillage.

Several styles of weaner pens are available. Floor pens, both partially slatted and non-slatted, raised decks and cages are used.

\section{FLOOR PENS}

Traditionally, weaned pigs have been placed in large groups (30-50) in floor pens $1200 \times 3000 \mathrm{~mm}$ (4 ft x 10 $\mathrm{ft}$ ) or $1200 \times 3600 \mathrm{~mm}$ ( $4 \mathrm{ft} \times 12 \mathrm{ft}$ ) in size. Typically, a self feeder is placed at the front of the pen and a slatted floor area at the rear of the pen. The front portion of the pen is heated using either a heat lamp and/or underfloor heat. Weaner pigs can be successfully raised in floor pens if attention is paid to cleanliness and maintaining an even temperature. Figure 37 shows this style of weaner pen.

\section{WEANER DECKS}

Weaner decks, flat decks, or cages are raised nursery pens used to grow pigs from weaning to $25 \mathrm{~kg}(55 \mathrm{lb})$. Pens range in size from $1.0 \mathrm{~m}^{2}$ to $3.2 \mathrm{~m}^{2}\left(10 \mathrm{ft}^{2}\right.$ to $\left.32 \mathrm{ft}^{2}\right)$. Pigs are allowed $0.2 \mathrm{~m}^{2} / \mathrm{pig}\left(2 \mathrm{ft}^{2} / \mathrm{pig}\right)$ in flat decks. Metal, plastic, and fibreglass flooring materials, all with a high percentage of open space, are available for flat decks.

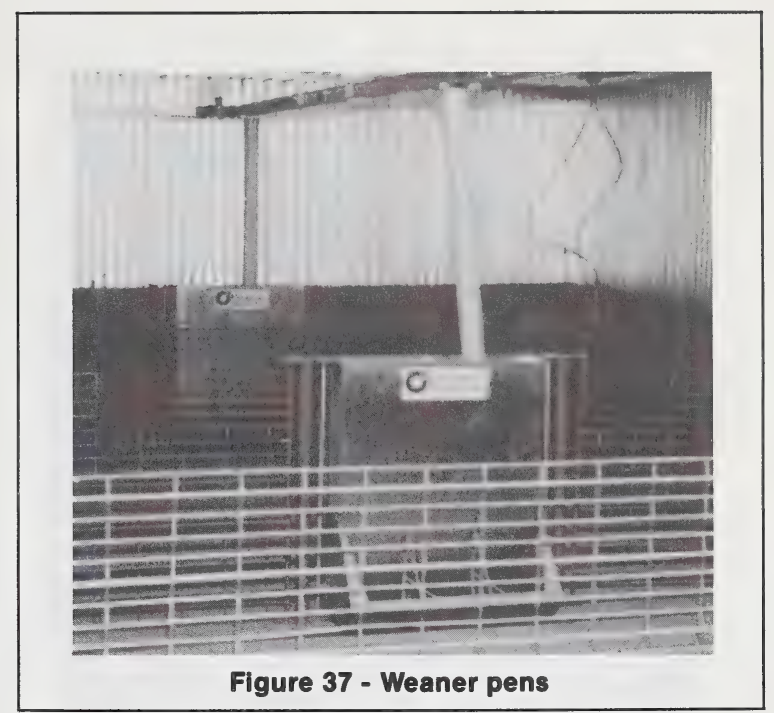

Several types of pig cage are used. Multi-level cages can be used. These cages are $1000 \mathrm{~mm} \times 1200 \mathrm{~mm} \times$ $450 \mathrm{~mm}$ ( $3 \mathrm{ft} \times 4 \mathrm{ft} \times 18 \mathrm{in}$.) and are stacked directly on top of each other. A fibreglass pan and manure scraper are placed between decks. Two or three levels of cages may be used depending on ceiling height.

Flat decks usually are $1.6 \mathrm{~m}^{2}$ or $3.2 \mathrm{~m}^{2}\left(16 \mathrm{ft}^{2}\right.$ or $\left.32 \mathrm{ft}^{2}\right)$ in size. They are raised about $600 \mathrm{~mm}(2 \mathrm{ft})$ above alley level and have a totally perforated floor. Figure 38 shows multilevel pig cages while Figure 39 shows a typical flat deck.

A third type of pig cage is one at the same level as the feeding alley. Perforated floors are used, except for $300-$ $600 \mathrm{~mm}(1-2 \mathrm{ft})$ at the front of the pen. This portion of the floor is heated to encourage the pigs to sleep here.

Weaner decks make better use of space in a hog barn. There can be up to $150 \%$ better utilization of space owing to multilevel pens and more pigs per unit of area. This can reduce investment in buildings and equipment. Weaner decks can be used very effectively when remodelling existing barns, where a limited space can be used to hold a large number of weaners.

Usually pigs in weaner decks are warmer and dryer than pigs in floor pens, however greater care must be taken with design and management of the heating and ventilation system to prevent drafts. Pigs in weaner decks grow more uniformly and there is less of a problem with runts. Pigs in weaner decks have up to $30 \%$ better weight gains than pigs in floor pens. Mortality is reduced by raising pigs in weaner decks. Typical mortality in decks may be $2 \%$ as compared to 4 $8 \%$ in floor pens. Scour problems are less frequent in weaner decks than on floor pens.

The use of weaner decks results in healthier pigs, better use of space and less work than raising pigs in flat decks. 


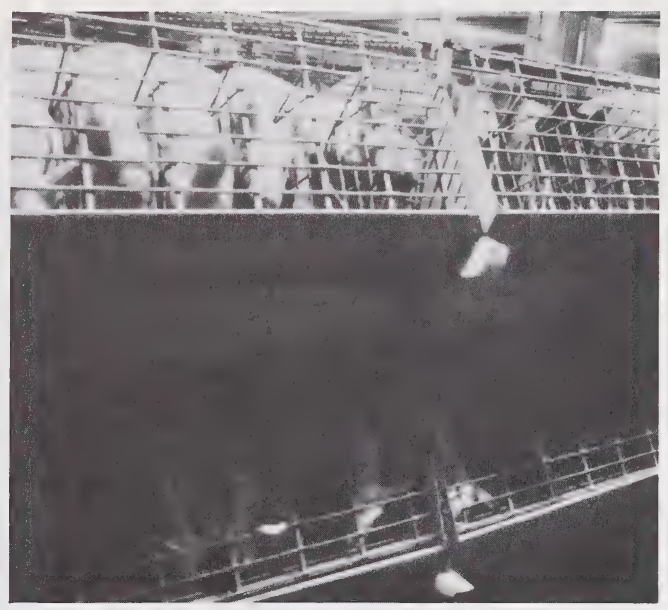

Figure 38 - Multi level pig cages for weaner pigs

There are some disadvantages to weaner decks. Lifting $25 \mathrm{~kg}(55 \mathrm{lb})$ pigs out of second and third level decks can be hard work. Costs of weaner decks tend to be higher than conventional pens.

Pigs in flat decks are usually on self-feeders. Feed spillage out of the feeder and subsequent wastage can be a problem. The choice of feeder can play an important role in feed wastage. The feed trough should have a $100 \mathrm{~mm}$ (4 in.) lip and an adjustable gap between

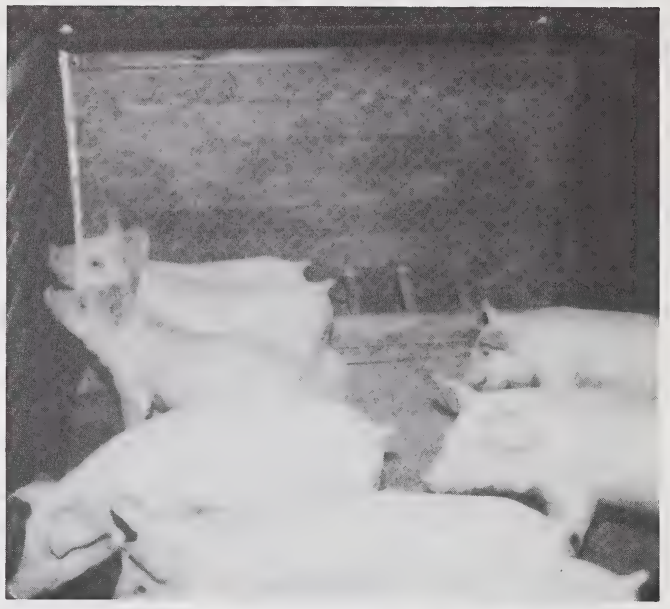

Figure 39 - Fiat deck for weaner pigs

the trough and the hopper. Well designed divisions in the feed trough help prevent feed wastage. A step or tray in front of the feeder may also help prevent feed wastage. Pigs should be discouraged from playing with the feed. Allow $50 \mathrm{~mm}$ ( $2 \mathrm{in}$.) of trough per pig or 2 pigs per feed hole.

Pigs should have access to clean potable water at all times. Nipple type waterers are used. Allow two nipples per pen, across the pen from each other. 
HOUSING THE

BREEDING HERD

THE GESTATION BARN: After weaning, sows are moved to the gestation barn to be bred and housed until farrowing. Many different types of gestation housing are used. Two basic classes of sow housing - indoor and outdoor housing - are common in our climatic conditions.

The principal function of gestation housing is to maximize the reproductive performance of the breeding herd.

\section{OUTDOOR SOW HOUSING}

The breeding herd, except farrowing sows, may be housed outside. Outside housing systems have the advantage of being relatively low cost. A very simple form of outside housing is to pasture the sows. Allow one hectare for every 33 to 40 sows. Shelters for the pigs to sleep in should be provided.

Another system of outdoor housing is to fence several outdoor runs. Sows can now be grouped in smaller groups. Pole shelters for sleeping and feeding can be constructed. Allow two openings into the sleeping area, which is bedded with straw, so that the boss sow cannot prevent other sows from entering the sleeping area.

Outdoor systems can be designed for hand breeding by including breeding pens in the layout. Sorting gates and alleys will ease animal movement and sorting. Many factors must be taken into account to accomplish this. The operators' preference in housing systems must be considered. A suitable environment must be provided for the housed breeding herd. As well, wastes must be removed from the building. Space must be allowed for the breeding herd, sows and boars and for replacement gilts. A well managed gestation barn has facilities that allow the animals normal reproductive behavior and does not put them under undue stress.

Group feeding is not a wise practice because if groups are larger than 4-6 sows the boss sow will get more than her share, while some other sow goes hungry. Feeding stalls 450 to $500 \mathrm{~mm}$ ( 18 to $20 \mathrm{in}$.) wide by $1800 \mathrm{~mm}$ (6 ft) long and $1050 \mathrm{~mm}$ (42 in.) high enable each sow to be fed as an individual. Sows can be self-fed using a practice known as skip-a-day feeding. Sow groups are allowed access to a self-feeder for 12-16 hours every other day.

Water is provided to sows housed outside by a variety of methods; the best system is to use an electrically heated automatic waterer.

If sufficient area is allowed for the sows, manure removal is not a problem. The housing area should be located on a well drained site. Surface drainage must not be allowed to contaminate lakes or streams.

Outdoor sow housing has disadvantages. In the winter sows cannot be brought directly out of a warm farrowing barn to cold outside housing. Feed requirements are also greater when sows are housed outside.

Fences for sows can be constructed of wooden planks, page wire, or an electric fence may be used. One very successful combination is a plank fence with an electric wire $150 \mathrm{~mm}$ ( $6 \mathrm{in}$.) above ground level and $150 \mathrm{~mm}(6$ in.) inside the fence. Figure 40 shows outdoor sow housing facilities.

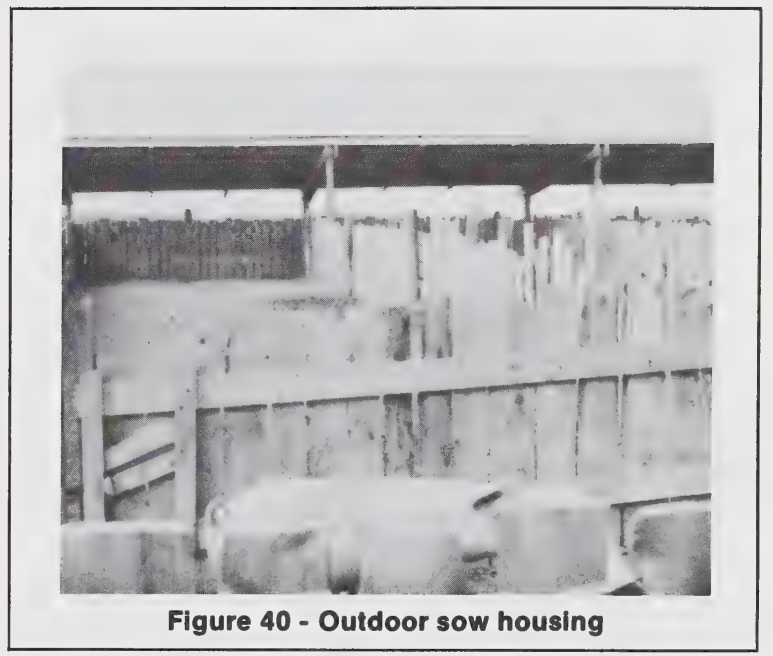

\section{CONFINED SOW HOUSING}

The breeding herd can also be housed indoors. Although labor requirements are reduced, a higher level of management is needed to successfully operate a confined gestation barn. The buildings tend to be costly, relative to outdoor housing. An operator may find increased foot and leg problems when he first moves into an indoor gestation unit, but these can be overcome by an aggressive culling program.

The following factors must be considered when designing indoor sow housing:

1. Environment, including temperature and ventilation.

2. Waste handling.

3. Floor material and floor design.

4. Space considerations, pen types, and the social interaction of the pigs.

5. Labor required to operate the unit.

6. Isolation of new breeding stock. 


\section{ENVIRONMENT}

The breeding herd can function in a wide range of temperatures. Temperatures in a confined controlledenvironment gestation barn can vary through the range $16-29^{\circ} \mathrm{C}$ with little apparent effect on the animals. Temperatures above $29^{\circ} \mathrm{C}$ cause heat stress in the animals.

Boars suffering from heat stress become temporarily sterile, even after short periods of stress. Recovery takes $6-9$ weeks.

Heat stress adversely affects the sow at all times during the gestation period. Embryo survival in a heat stressed sow is poor. However, the most critical time is in the period up to 3 weeks after breeding.

Temperatures below $13^{\circ} \mathrm{C}$ require more feed for the housed herd. The extra feed is used to keep the animals warm.

\section{SPACE REQUIREMENTS}

A breeding gestation barn must be large enough to house the breeding herd. Normally space is allowed for $75 \%$ of the sow herd, replacement gilts and boars. Allow space for 3 to 6 times the number of gilts needed for replacement so that there will be a sufficient number of gilts in heat when they are needed. Normally one boar is allowed per 20 sows.

Pen layout in the gestation barn affects its success. For efficient breeding the boar should be penned next to the sows to be bred. Gates and passageways allow for ease of access to move the boar and sows.

Gilts must be housed for reproduction stimulation. Gilts are housed in small groups in pens. Stress to induce estrus can be applied by regrouping gilts, or placing a sow in the gilt groups. Gilt pens should be next to a working boar so that he can be easily moved into the pen. Lighting for the gilts should be 14 to 18 hours per day at a level of 100 to 200 lux (10 to 20 foot candles). Gilts must not be housed in individual stalls.

Equipment for housing the sow herd can take the form of group pens, tie-stalls or tethers and individual stalls.

\section{PENS}

Partially slatted pens are used to house gilts and sows. A $1500 \times 4800 \mathrm{~mm}(5 \mathrm{ft} \times 16 \mathrm{ft})$ pen will house 4 to 5 sows. Partitions should be open and have vertical dividers to maximize pen to pen communications between sows and boars. Partition height should be a minimum of $1050 \mathrm{~mm}$ (42 in.). Penned sows can be floor fed or individual feed stalls may be used.

Pens for sow housing have lower costs than other forms of confined sow housing. The animals in the pen are more visible to the manager, which allows for easier heat detection. Because sows in a group pen can huddle, a lower room temperature, between $13-16^{\circ} \mathrm{C}$, can be used. A waterer is provided over the slat area.

Social problems within the sow groups may be a problem when sows are housed in pens. No more than 4-6 sows should be grouped together. Individual feeding of the sows is impossible so there is little control over an individual sow's intake. Sows tend to be irritable and poor housekeepers. Some problems with dirty pens may be experienced. Figure 41 shows group pens for sows.

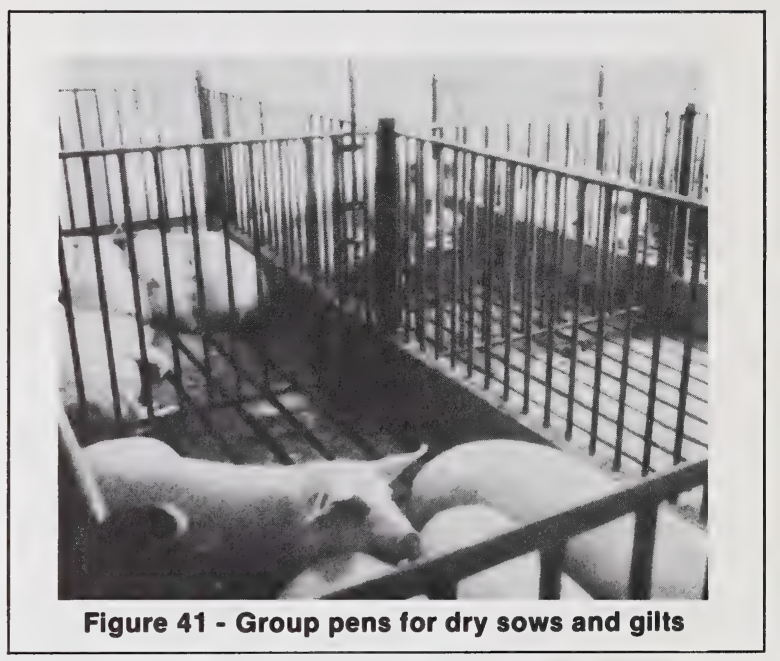

\section{INDIVIDUAL STALLS}

Individual sow stalls or gestation stalls are used to house the sows individually. They consist of a crate like structure with a feed trough at the front and a gate at the rear. Usually there is $600-900 \mathrm{~mm}$ (20 in. to $30 \mathrm{in}$.) of slat length at the rear of the stall. Stall dimensions are $450 \mathrm{~mm}$ to $600 \mathrm{~mm}$ (18 in. to $24 \mathrm{in}$.) wide, $2000 \mathrm{~mm}$ ( $7 \mathrm{ft}$ ) long and 975 to $1000 \mathrm{~mm}$ (34 in. to $40 \mathrm{in}$.) high. Metal tubing is usually used to construct stalls. Feeding may be in a feed trough formed on the floor at the front of the stall or in a feeder in the front gate of the stall. Water may be supplied by individual waterers or in a trough formed in the concrete.

Individual feeding of sows in stalls is very easy and can be automated. Sow identification is also easier when sows are housed in stalls.

Stalls tend to have a high capital cost to install. Building temperatures must be $20^{\circ} \mathrm{C}$ or higher because the sows cannot huddle or otherwise modify their environment. Heat detection of sows in crates is a problem. Neither the operator or a boar can accurately determine whether or not a sow is in heat. Some sows may object to being housed in stalls and will either need to be culled or housed in pens. Rows of stalls shoud face each other so that the sow can see the face of other sows (Figure 42). 


\section{TETHERS OR TIE STALLS}

A tether stall is one in which the sow is tied or tethered. One form of tether is placed immediately behind the sow's front legs and tied to a ring in the floor. Old seat belts or commercially made units may be used as tethers. The tether stall is similar to the tie stall. Dividers are about $1500 \mathrm{~mm}(5 \mathrm{ft})$ long, the width is 450 to 600 $\mathrm{mm}$ (18 in. to $24 \mathrm{in}$.) and the height is 975 to $1000 \mathrm{~mm}$ (34 in. to $40 \mathrm{in.}$.).

Equipment for tether stalls is less costly than for individual stalls, but more costly than pens. There is good access to and visibility of sows housed in tether stalls. Sows in tethers can be individually fed.

Some sows do not like tethers and must be culled or housed in pens. Heat detection of tethered sows is difficult. As with individual stalls, the barn temperature must be $20^{\circ} \mathrm{C}$ or higher. Figure 43 shows one type of tether or stall.

In addition to sow housing, other types of pens are also needed in the gestation barn. These include heat check pens, boar pens and breeding pens.

\section{HEAT CHECK PENS}

Sows are normally bred 4-6 days after weaning and again are heat checked 21 days after breeding. In a barn with sow stails it is easier to heat check the sows if they are moved to a heat check pen. The heat check pen should be easily accessible to the boar. It may also double as a breeding pen.

\section{BOAR PENS}

Boars should be individually housed. Allow 4-5 $\mathrm{m}^{2}(40$ to $50 \mathrm{ft}^{2}$ ) per boar. Boar pens should be located next to sows and to the breeding pens. Boars may be housed in a portion of the breeding pen, i.e. over the slats. Allow one boar per 20 sows.

\section{BREEDING PENS}

Locate the breeding pens to allow easy movement of sows and boars. Gates should be located for ease of operation and animal movement. The minimum size for a breeding pen is $2400 \mathrm{~mm} \times 2400 \mathrm{~mm}$ ( $8 \mathrm{ft} \times 8 \mathrm{ft}$ ). An essential feature of the breeding pen is a dry non-slip floor. Sand is an excellent material. An alternative is a non-slip concrete surface.

\section{WATER AND FEED}

Several methods exist of watering sows. One of the simplest is a common trough poured in the concrete floor at the front of the individual stalls. A float valve maintains a constant water level. This trough may also be used for feeding. The water is shut off before feeding and turned on afterwards. The bottom of this trough should be no lower than the level of the sow's feet and there should be a divider between each sow stall.
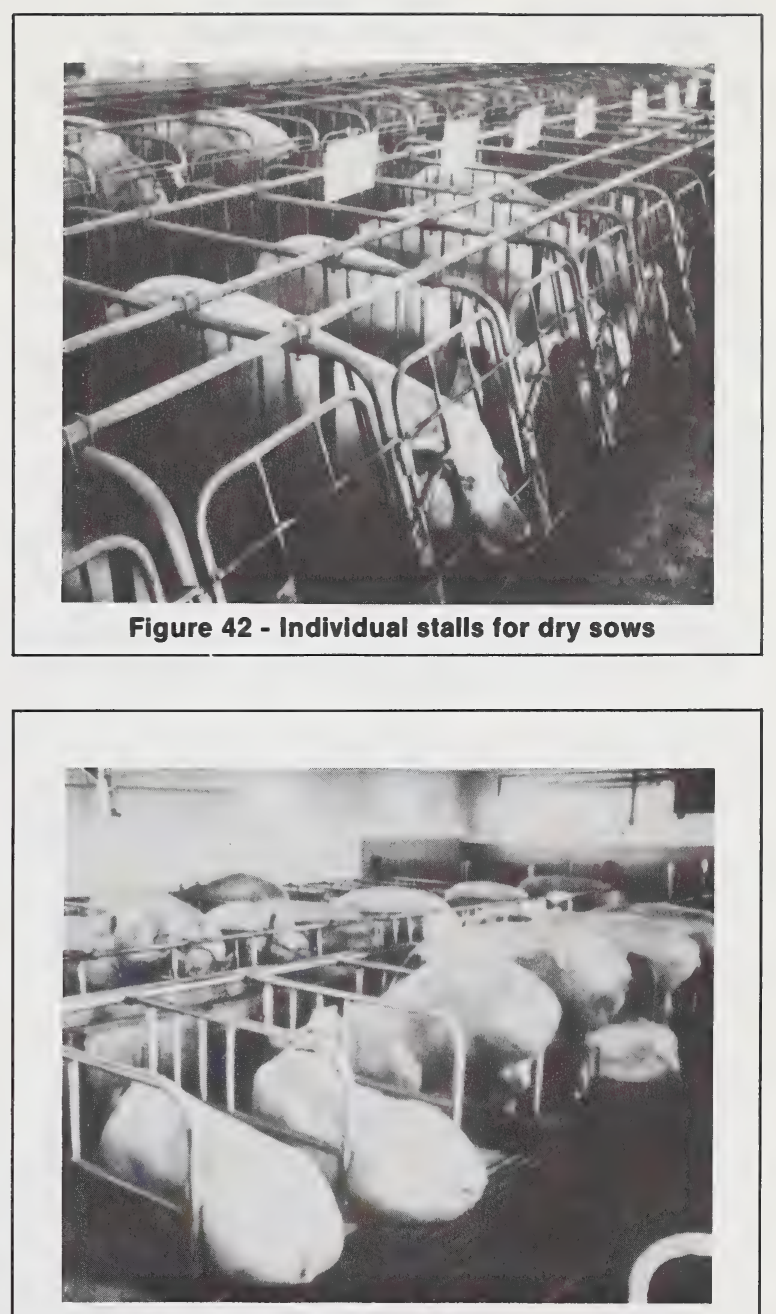

Figure 43 - Tie stall for containing dry sows

Nipple waterers may also be used. These should be mounted so that the sow has to reach for the nipple. In a pen nipples are usually mounted in one corner and over the slatted floor area. In stalls nipples are mounted at the front and in some cases over the feed trough.

In a confined barn where sows are individually penned feeding may be done by hand or mechanically. In this situation some method of surprise feeding of the sows is advantageous. A homemade system or a commercial system may be used. The feed delivery system must be filled while the sows are eating.

\section{FACILITIES FOR NEW BREEDING STOCK}

Another consideration is the housing of newly acquired breeding stock. New stock should be housed away from the main herd until its health status has been determined. 


\section{FEEDER HOUSING AND EQUIPMENT}

A well designed feeder barn is easily automated and requires a minimum amount of labor. Automated drop feeders, self-feeders, or manual floor feeding may be used. Manure can be handled as a solid or as a liquid. The common system is to handle manure as a liquid.

Frame type buildings and rigid frame buildings are commonly used as hog feeder barns. Other building styles, such as pole buildings, can also be used. All buildings must be adequately insulated - RSI 3.5 (R20) walls and ceiling and RSI 1.4 (R8) foundation insulation.

Figure 44 shows the layout of a good hog pen. It is long and narrow, has curbs for the pigs to lie against and has distinct manuring, eating and sleeping areas. The short cross partition assists in establishing good manuring patterns.

Pens in a feeder barn are proportioned one wide by three long. A typical size is $1800 \times 4800 \mathrm{~mm}$ ( $5 \mathrm{ft} \times 16 \mathrm{ft}$ ). This size of pen will hold 20 growing pigs or 10 finishing pigs. When the 20 growers become crowded in one pen, they are split into two groups of 10 and placed in two pens.

Another system is to use a barn with two pen sizes. A small pen $1200 \times 3900 \mathrm{~mm}(4 \mathrm{ft} \times 13 \mathrm{ft})$ is used to hold the growing pigs. A $1500 \times 4500 \mathrm{~mm}(5 \mathrm{ft} \times 15 \mathrm{ft})$ pen is used for finishing pigs. This system minimizes social stress on the pigs caused by splitting or changing groups.

Pen floors should have a smooth non-slip surface and slope $1: 25$ towards the gutter. About $30 \%$ of the pen area should be slatted, in the case of partially slatted

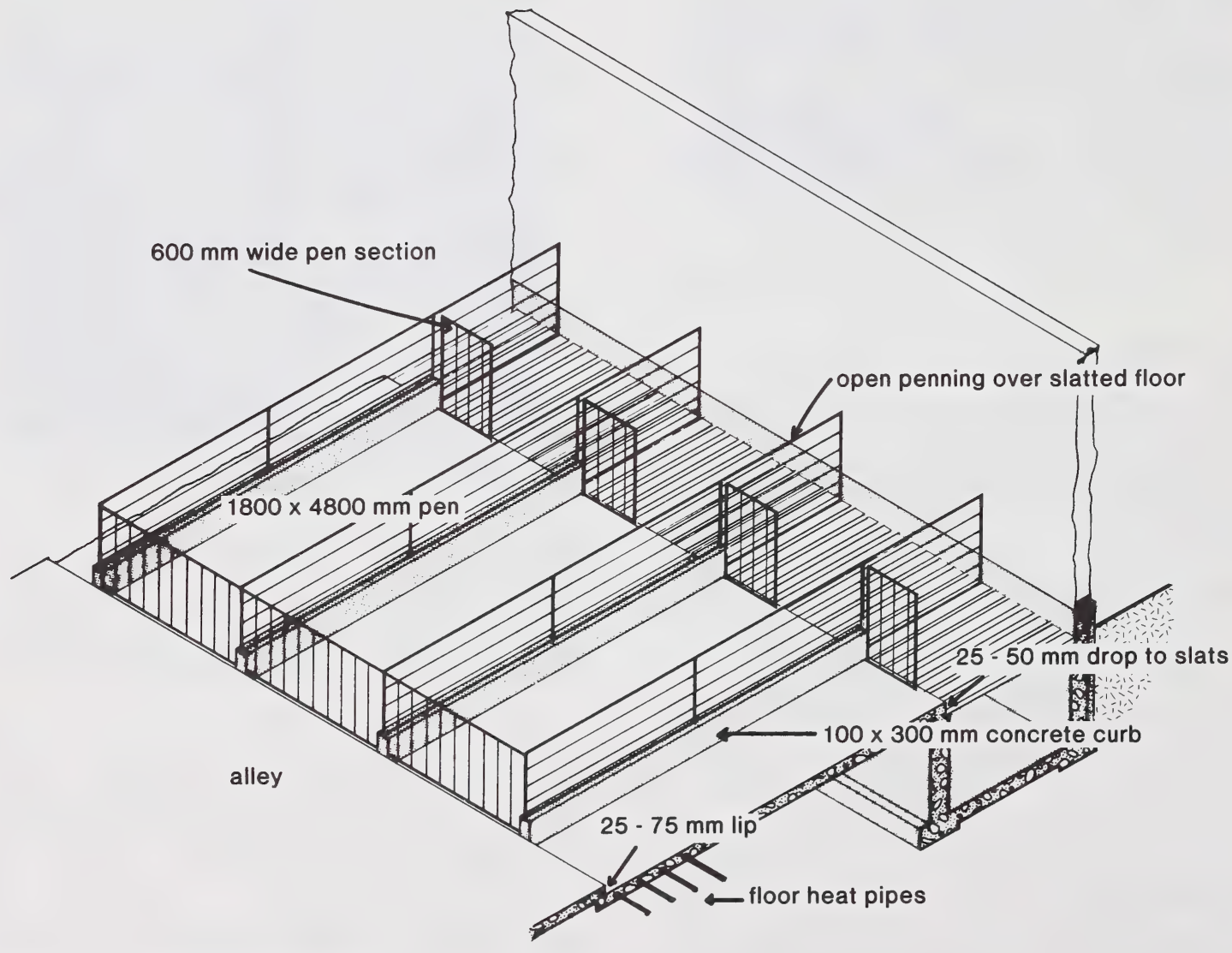

Figure 44 - This is a good hog pen. Note curbs over solid floor and open gates over gutter 
floors. Heat, in the form of underfloor hot water pipes,

can be placed under the sleeping area of the pen to

provide a more comfortable environment for the pig.

Concrete slats $75-200 \mathrm{~mm}$ ( 3 in. to $8 \mathrm{in}$.) wide are commonly used in feeder barns. They may be precast or cast in place. There should be a 25 to $50 \mathrm{~mm}$ ( $1 \mathrm{in}$. to 2 in.) drop from the floor area to the slatted floor area. Slats should be spaced 25 to $32 \mathrm{~mm}$ ( 1 to $1.5 \mathrm{in}$.) apart. Other slats such as fibreglass, aluminum, metal and plastic are also available.

The following list provides construction and management guidelines that may help control manuring patterns in a partially slatted floor feeder barn.

1. Use a solid pen partition over the solid floor. Alternately use a $100 \times 300 \mathrm{~mm}$ ( 4 in. $\times 12$ in.) curb.

2. Use an open, or mesh, type divider over the slatted floor area.

3. Place feeder in the sleeping area. Use pen-line feeders as part of the pen partition.

4. Locate waterer at the rear of the slatted area.

5. Use zone or floor heating in the sleeping area during periods of cold temperature.

6. Provide a step of $25-50 \mathrm{~mm}$ ( $1 \mathrm{in}$. to $2 \mathrm{in}$.) from the floor to the slats.

7. Prevent drafts in the sleeping area.

8 . Wet the slatted area immediately before placing pigs in the pen.

9. Feed on the floor for the first few days.

10. Provide the correct amount of floor space per pig.

11. During hot weather use a sprinkler cooling system. 
SWINE FEED

PROCESSING AND

HANDLING

Production of a $100 \mathrm{~kg}(220 \mathrm{lb})$ hog requires $400-500 \mathrm{~kg}$ (880-1000 lb) of feed. Planning of feed processing and handling is required to minimize the expense and labor of processing, storing, handling and distributing feed.

Feed for the swine operation can be purchased as a complete ration, or it can be processed on the farm using farm produced grains and commercial supplements. Special products such as starter rations, crumbles and pellets will probably be purchased as they do not lend themselves to farm processing.

Other options open to the swine producer include the hauling of grain to a custom mill to be processed, having a mobile custom mill come to the farm, or processing feed on the farm. Hauling grain to a custom mill to be ground and mixed with supplements can be costly and time consuming. A mobile custom mill can process farm grown grains, add supplements, and place a complete ration into feed storage bins. On-farm feed processing requires capital investment and the ability of the manager to process and mix suitable rations.

Three operations are required for on-farm feed processing:

- accurate measurement of ingredients

- grinding

- mixing of ingredients.

These operations can be handled by assorted equipment.

\section{PROPORTIONING EQUIPMENT}

Proportioners or auger meters are common to on-farm feed processing. They function by volumetric proportioning and are continuous in metering. Accuracy varies depending on auger speed, and the characteristics of the material being metered. Very fine materials do not meter accurately. Usually several augers, one for each ingredient to be included in the ration are assembled into a unit. This unit is then mounted over the mill. Each auger in the unit must be calibrated for the material being metered. Periodic checks on the accuracy of metering are advisable. Calibration should also be checked when new sources of grain and supplement are used. Figure 45 shows a proportioner mounted on an electrically driven hammer mill.

Vibrating meters are also used. These consist of a box with a trough and an adjustable gate. An electric vibrator is attached to the bottom of the trough. Output

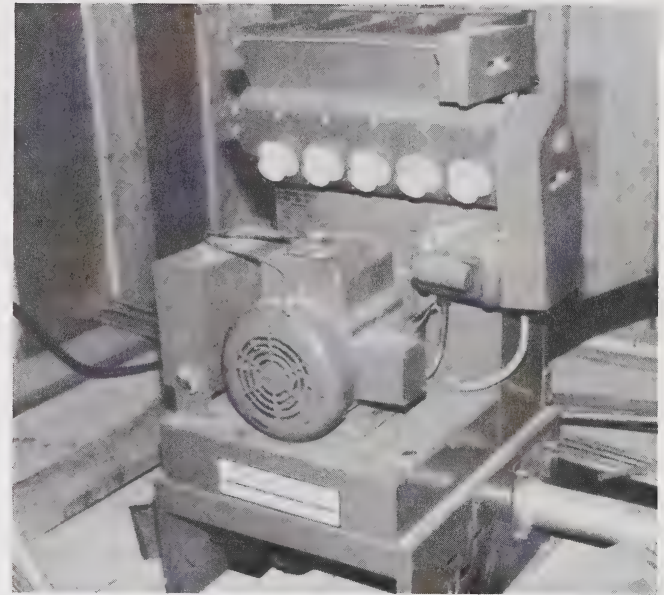

Figure 45 - Proportioning grinder-mixer

is changed by varying the frequency of the vibrations and the gate opening. The meter is accurate for free flowing materials including fine materials.

Weigh scales are the most accurate method of mixing a ration. However, this requires the handling of ingredients in batches. A batch system using scales may be difficult to automate.

Other types of meters that can be considered are belt type meters and dump type meters.

After the ration ingredients have been proportioned they are ground. Swine rations are finely ground to aid digestibility. Hammer mills and burr mills produce a finely ground feed suitable for swine.

\section{BURR MILLS}

A burr mill is made up of two roughened metal plates, one stationary and the other rotating. Material to be ground is fed into the space between the plates and

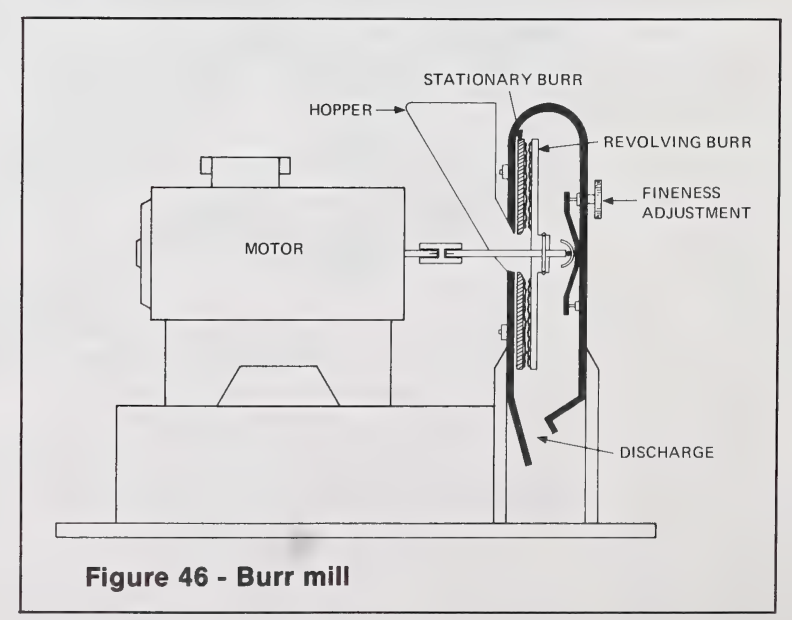


crushed and pulverized. Fineness of grind is controlled by regulating the space between the plates. Figure 46 shows a burr mill.

\section{HAMMER MILLS}

A hammer mill consists of rotating hammers inside a heavy perforated screen. The hammers strike the material fed into the mill and pulverize it until it is reduced in size enough to pass through the screen. The fineness depends on the screen size. The finer the screen, the more power required to grind the material and the less the capacity of the mill. Figure 47 shows a hammer mill.

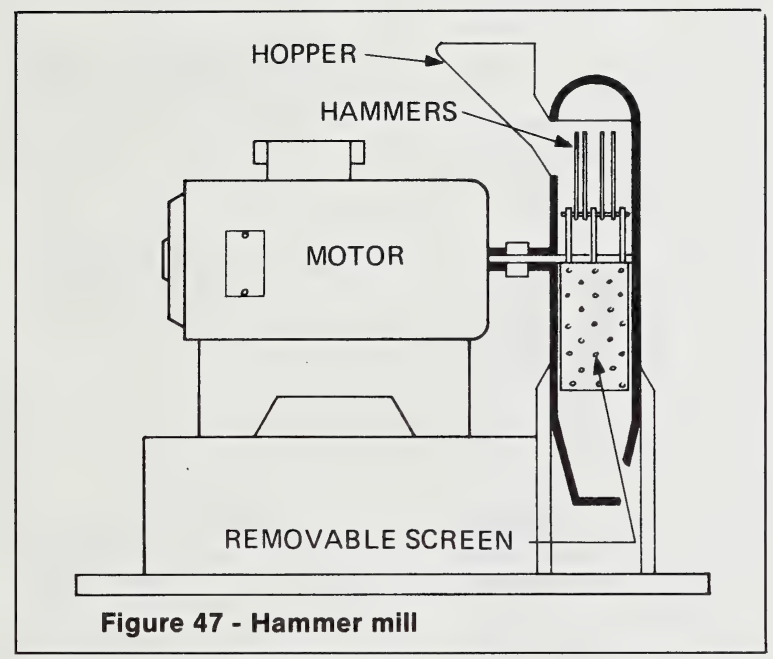

Hammer mills used for on-farm processing of swine feeds are generally in the 2 to $7.5 \mathrm{~kW}$ (2.5 to $10 \mathrm{hp}$ ) size range, and fitted with a proportioner. Approximate capacities will range from $100 \mathrm{~kg}$ to $320 \mathrm{~kg}$ (200 to 650 Ib) per hour.

\section{MIXERS}

Mixing of the complete feed can be accomplished by continuously proportioning feed ingredients into the mill. Alternatively, individual ingredients can be weighed (batched), milled and mixed, using either a horizontal or vertical mixer shown in Figure 48.

Horizontal mixers do a faster, more thorough job of mixing than vertical mixers. They do, however, require more power than vertical mixers.

After the feed has been formulated it is moved to storage. Typically, this is a feed bin located near the hog operation.

Typically, a minimum of 3 rations must be stored. Bulk rations may be stored in hopper bottom bins. Bagged feeds can be stored in a feed room. Bulk rations are moved by conveyor into the building.
Swine can be limit-fed or self-fed. In either case, feed may be delivered by hand or by mechanical conveyor. A feed cart can be used for hand feeding.

Several types of conveyors are used to move feed around the hog barn. They are pneumatic, coreless auger, auger, cable and chain types of conveyors.
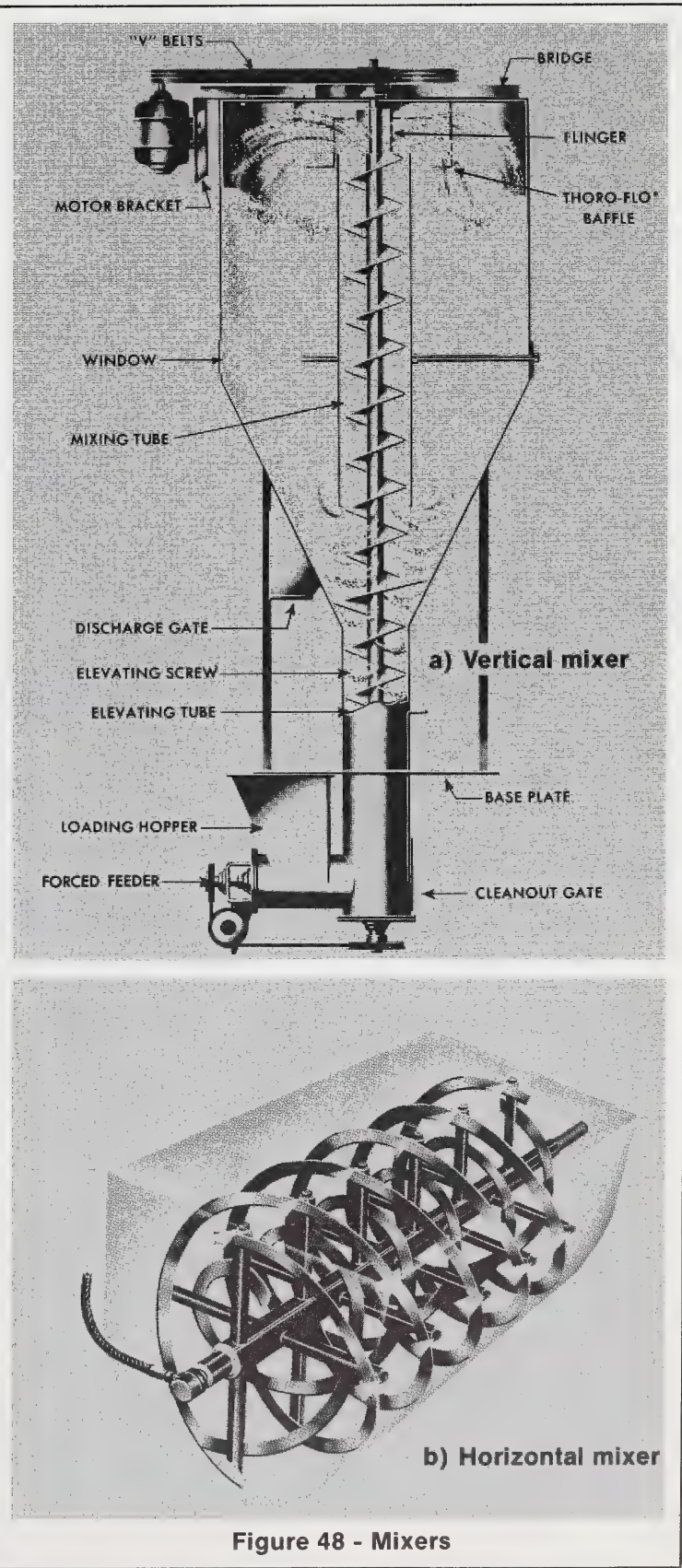


\title{
FURTHER INFORMATION AVAILABLE FROM
}

\author{
Many aspects of planning and constructing a hog barn \\ have been discussed. Planning assistance and barn \\ plans are available from Alberta Agriculture's regional \\ engineers and swine specialists. Engineers and swine \\ specialists are located in the following Alberta \\ Agriculture offices and may be contacted directly or \\ through your district agriculturist:

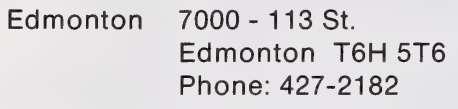

Airdrie

Bag Service \#1

Airdrie TOM OBO

Phone: 948-5101

$\begin{array}{cl}\text { Fairview } & \begin{array}{l}\text { Box } 7777 \\ \text { Fairview } \\ \text { Phone: } 835-2291\end{array} \\ \text { Red Deer } & \begin{array}{l}\text { Box } 5002 \\ 4920-51 \text { Street } \\ \text { Red Deer T4N 5Y5 } \\ \text { Phone: 343-5323 }\end{array} \\ \text { Barrhead } & \begin{array}{l}\text { Box 1540 } \\ \text { Barrhead T0G 0E0 } \\ \text { Phone: } 674-3351\end{array} \\ \text { Vermilion } & \begin{array}{l}\text { Box 330 } \\ \text { Vermilion TOB 4M0 } \\ \text { Phone: 853-2811 }\end{array} \\ & \end{array}$




\section{APPENDIX}

TABLE A - SPACE REQUIREMENTS FOR SWINE

\section{Accommodation \\ Feedlot \\ hard surfaced area \\ pasture area \\ Confinement housing solid floor pen area}

Slotted floor pens total pen floor area

slotted floor area

slot width

slat width

Partition height

Self-feeder length

Feed trough length

Individual feeding stall

dimensions

Gestation tie stall

width

length, feed trough

to gutter

to slotted floor

\section{Gestation pen stall}

width

length

height

Farrowing pen dimensions side creeps, early weaning side creeps, late weaning front creep

clearance under partition

\section{Sows}

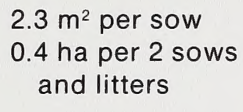
$1.8 \mathrm{~m}^{2}$ per sow under $180 \mathrm{~kg}$
$2.0 \mathrm{~m}^{2}$ per sow
over $180 \mathrm{~kg}$

$$
\begin{gathered}
1.5 \mathrm{~m}^{2} \text { per sow } \\
\text { under } 180 \mathrm{~kg} \\
1.9 \mathrm{~m}^{2} \text { per sow } \\
\text { over } 180 \mathrm{~kg}
\end{gathered}
$$

$35-100 \%$
$25-32 \mathrm{~mm}$
$38-230 \mathrm{~mm}$

$1070 \mathrm{~mm}$

(not recommended)

450-600 $\mathrm{mm}$ per sow

$450 \mathrm{~mm}$ wide

600-1800 $\mathrm{mm}$ long

$600-700 \mathrm{~mm}$

1450-1650 mm

$1200 \mathrm{~mm}$

$660 \mathrm{~mm}$

$1800 \mathrm{~mm}$

$1060 \mathrm{~mm}$

$1500 \times 2100 \mathrm{~mm}$ $1800 \times 2100 \mathrm{~mm}$ $1500 \times 2700 \mathrm{~mm}$ 200-250 mm

\author{
Weaners \\ (under $22 \mathrm{~kg}$ )
}

$0.75 \mathrm{~m}^{2}$ per pig

0.4 ha per 25 pigs

$0.2-0.4 m^{2}$ per pig

$$
\begin{gathered}
0.2-0.3 \mathrm{~m}^{2} \\
\text { per pig }
\end{gathered}
$$

$30-100 \%$ (100\% preferred)

9 or $25 \mathrm{~mm}$

38-130 mm

$700 \mathrm{~mm}$

$50 \mathrm{~mm}$ per pig

$250 \mathrm{~mm}$ per pig
Feeders

(22-90 kg)

$1.9 \mathrm{~m}^{2}$ per pig

0.4 ha per 10 pigs

$0.5 \mathrm{~m}^{2}$ per pig
under $45 \mathrm{~kg}$
$0.8 \mathrm{~m}^{2}$ per pig
$45 \mathrm{~kg}-90 \mathrm{~kg}$

$0.35 \mathrm{~m}^{2}$ per pig $22-45 \mathrm{~kg}$

$0.5 \mathrm{~m}^{2}$ per pig 45-67 kg

$0.7 \mathrm{~m}^{2}$ per pig $67-90 \mathrm{~kg}$

$30-100 \%$

25-32 mm

38-230 mm

$900 \mathrm{~mm}$

$75 \mathrm{~mm}$ per pig

$330 \mathrm{~mm}$ per pig 


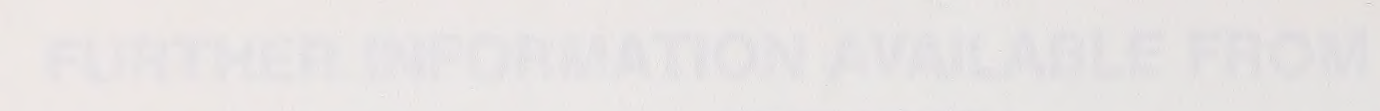

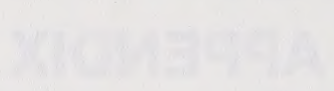



